Portland State University

PDXScholar

1979

\title{
The systhesis and photolysis of 1-phenylcyclohexaneacetic acid azide
}

Jack P. Mourad

Portland State University

Follow this and additional works at: https://pdxscholar.library.pdx.edu/open_access_etds

Part of the Chemistry Commons

Let us know how access to this document benefits you.

Recommended Citation

Mourad, Jack P., "The systhesis and photolysis of 1-phenylcyclohexaneacetic acid azide" (1979).

Dissertations and Theses. Paper 2779.

https://doi.org/10.15760/etd.2775

This Thesis is brought to you for free and open access. It has been accepted for inclusion in Dissertations and Theses by an authorized administrator of PDXScholar. Please contact us if we can make this document more accessible: pdxscholar@pdx.edu. 
AN ABSTRACT OF THE THESIS OF Jack P. Mourad for the Master of Science in Chemistry presented February 23, 1979.

Title: The Synthesis and Photolysis of 1-Phenylcyclohexaneacetic Acid Azide.

APPROVED BY MEMBERS OF THE THESIS COMMITTEE:

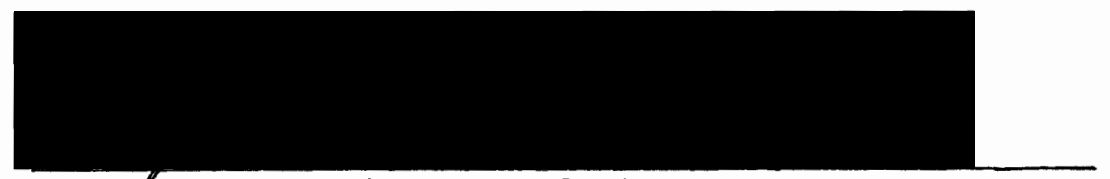

Alfrea S. Levinson, Chairman
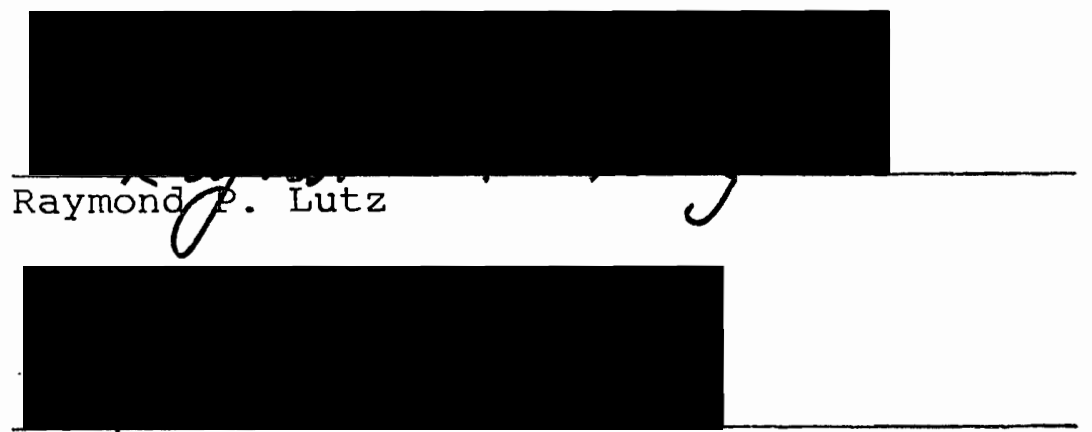

Norman C. Rose

The aim of this research project was to study the possible synthesis of the morphine analog 3-oxo-5-phenylmorphan (2) via the photochemical cyclization of the acyl azide (1) of 1-phenylcyclohexaneacetic acid:

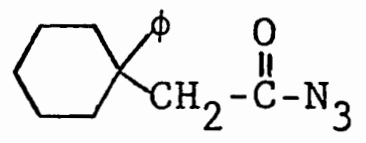

(1)

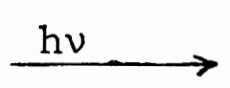

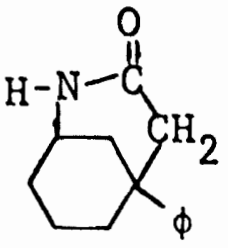

(2) 
Treatment of 1-phenylcyclohexaneacetic acid with thionyl chloride afforded the corresponding acid chloride. The latter was converted to the acyl azide (1) by an aqueous solution of sodium azide in dioxane.

The photolysis of the azide was carried out successfully in hexane at $15-20^{\circ}$ for one hour. High pressure liquid chromatography and column chromatography on silica gel were utilized to purify the crude photolysis mixture. Infrared and nuclear magnetic resonance data were used to determine the structures of the photolysis products.

It was found that 1 -phenylcyclohexylmethyl isocyanate (3) was the major product isolated from the crude photolysis mixture (ca. 40\%). A white solid, tentatively identified as the desired $\delta$-lactam 3-oxo-5-phenylmorphan (2), was also obtained in about $13 \%$ yield.

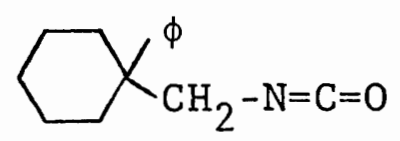

It was proposed that the isocyanate was produced via the Curtius rearrangement of the azide whereas the lactam (2) resulted from insertion of the intermediate acyl nitrene into $\mathrm{C}-\mathrm{H}$ bond of the cyclohexane ring. 
THE SYNTHESIS AND PHOTOLYSIS OF 1-PHENYLCYCLOHEXANEACETIC ACID AZIDE

by

JACK P. MOURAD

A thesis submitted in partial fulfillment of the requirements for the degree of

\author{
MASTER OF SCIENCE \\ in \\ CHEMISTRY
}

PORTLAND STATE UNIVERSITY

1979 
TO THE OFFICE. OF GRADUATE STUDIES AND RESEARCH

The members of the Committee approve the thesis of Jack P. Mourad presented February 23, 1979.

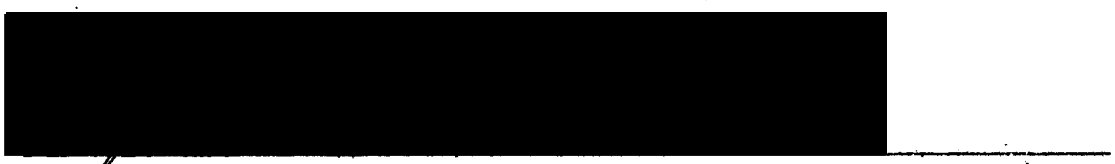

Alfred S. Levinson, Chairman
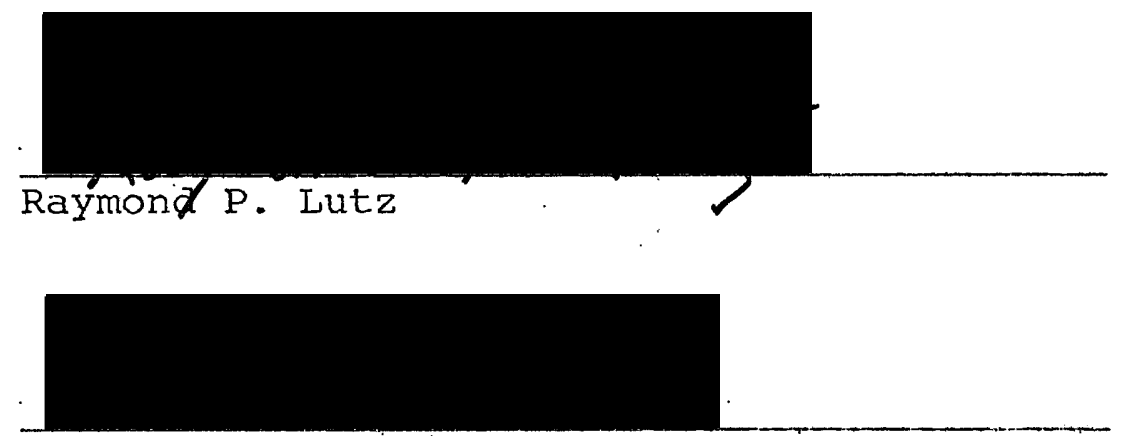

Norman C. Rose

APPROVED :

D.W. McClure! Chairman, Department of Chemistry

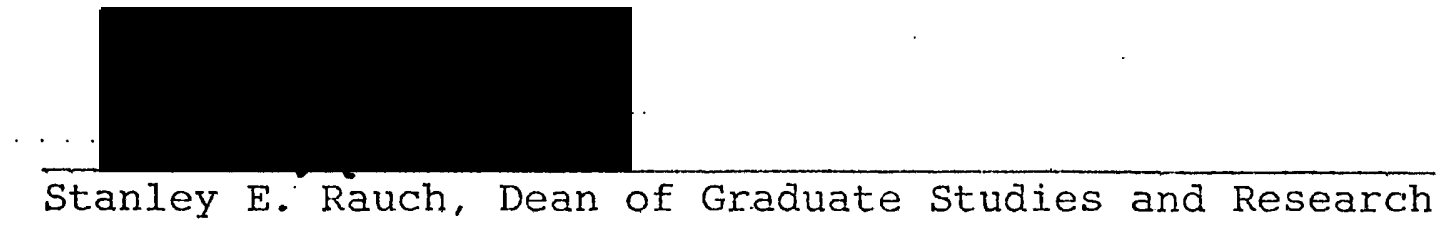


TABLE OF CONTENTS

PAGE

LIST OF TABLES • • • • • • • • • • • • • • •

LIST OF FIGURES • • • • • • • • • • • • •

CHAPTER

I INTRODUCTION • • . : . • • • • • •

II REVIEW OF THE LITERATURE • • • • • •

Acyl Azide Photolysis:

scope, limitations

and mechanism

III DISCUSSION . • . . . . . . . . . .

IV EXPERIMENTAL $. . . \cdot . \cdot . \cdot . \cdot \cdot \cdot \cdot \cdot$

$\mathrm{V}$ CONCLUSIONS • . . . . . . . . . . .

VI SUGGESTIONS FOR FURTHER WORK

REFERENCES 


\section{LIST OF TABLES}

TABLE

PAGE

I Examples of Acyl Azide Photolysis . . . .

I Product Data for Three Preparations of

1-Phenylcyclohexaneacetyl Chloride . .

III General Photolysis Conditions, IR Carbonyl

Absorptions and Methods of Separation of the Crude Mixture . . . . . . . . 


\section{LIST OF FIGURES}

FIGURE

PAGE

1 Photolysis Apparatus . . . . . . . . 
INTRODUCTION

Morphine (1) is the prototype drug for pain relief. However, the problems of opiate addiction and the associated social trauma have served to intensify the search for a better analgesic which has no harmful side effects and does not induce physical dependence. It has been observed that simple synthetic morphine-like compounds, such as certain morphinans and benzomorphans (e.g. 2, 3) are as effective as or more effective than morphine

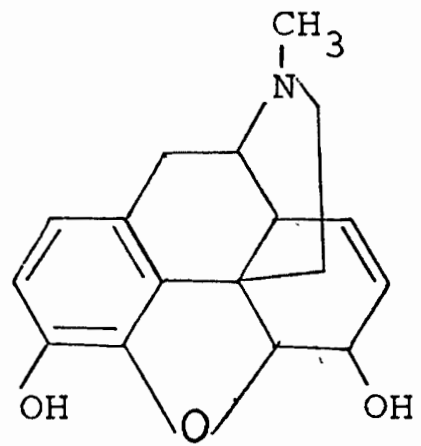

(1)

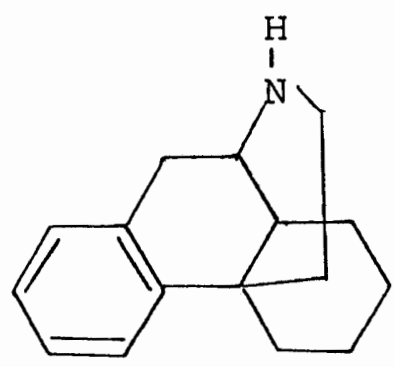

(2)

morphine

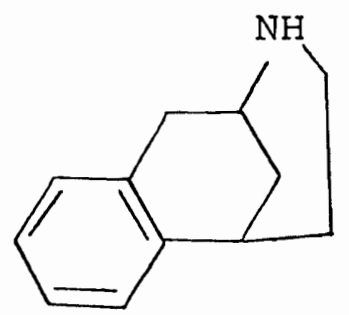

(3)

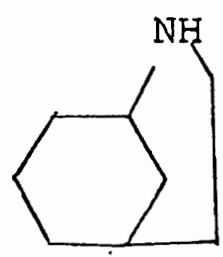

(4)

morphan 
in relieving pain. These compounds contain only a portion of the morphine structure, known as the morphan ring system (4) or azabicyclo [3.3.1] nonane. Unfortunately, many of these compounds also have the undesirable side effects of morphine.

The aim of this research project was the synthesis of the morphine analog 3-oxo-5-phenylmorphan (6). It was anticipated that (6) could be prepared by the photochemical cyclization of the acyl azide (5) of I-phenylcyclohexaneacetic acid, for which precursors were available.

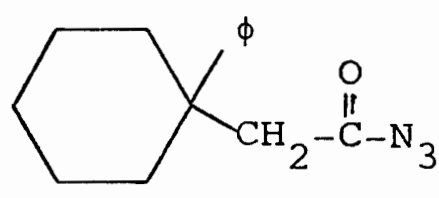

(5)

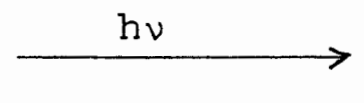

The photochemical decomposition of the acyl azide should normally generate an electron-deficient monovalent nitrogen species referred to as an acyl nitrene (7). It was expected that the morphan ring system would be. formed via an intramolecular cyclization of the shortIived acyl nitrene intermediate (7) by insertion into a $\mathrm{C}-\mathrm{H}$ bond, yielding the amidic product (6).

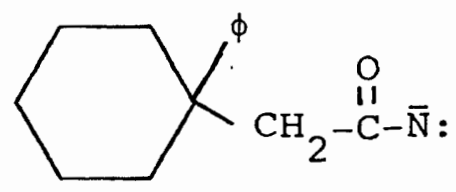


CHAPTER II

REVIEW OF THE LITERATURE

ACYL AZIDE PHOTOLYSIS: scope, limitations and mechanism.

In the last 20 years, the chemistry of azides has been the subject of intensive investigations because of their importance in preparative heterocyclic chemistry. Specifically, the photolysis of acyl azides has played an important role in natural products synthesis and structure determination.

The first photolysis of an acyl azide was performed by ApSimon and Edwards ${ }^{1}$ in order to help establish the structure and stereochemistry of the diterpene alkaloid atisine (8). They prepared the acyl azide (9) of IBcarboxy-l $\alpha, 12 \beta$-dimethyl-trans-anti-cis-perhydrophenanthrene in which ring $C$ should provide 'steric compression of the angular methyl group, forcing it unusually close to the axial carboxyl. The acyl azide (9) was subjected to ultraviolet irradiation. Although the major product was the corresponding isocyanate (10) in $70 \%$ yield, the $\delta$-lactam ( 11 ) was obtained in $25 \%$ yield and a trace of a $\gamma$-lactam (12) was isolated. The formation of the $\delta$ lactam (1l) could well have been due to steric compression of the angular methyl group $(C-17)$ by ring C. Apsimon 


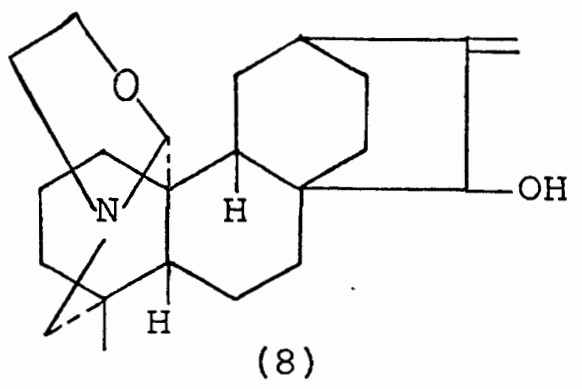

atisine

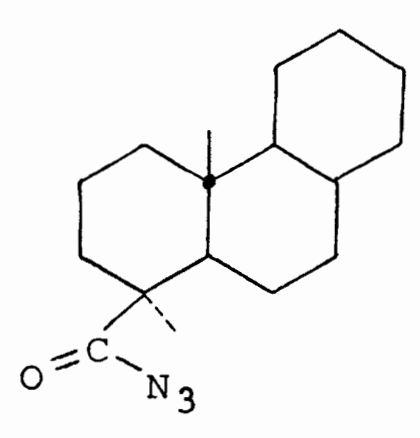

(9)

$$
\text { or }
$$

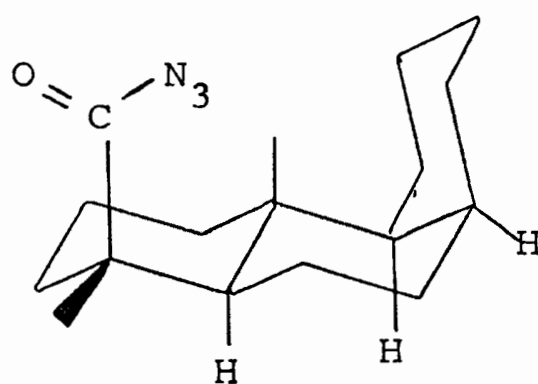

(9)

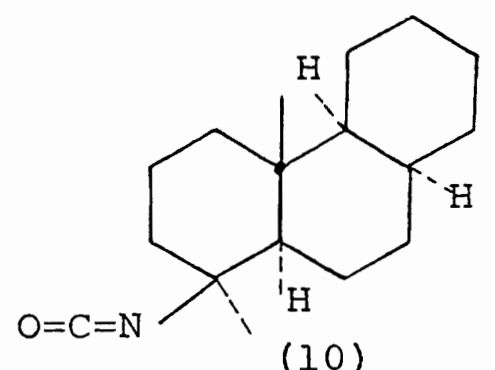

(10)

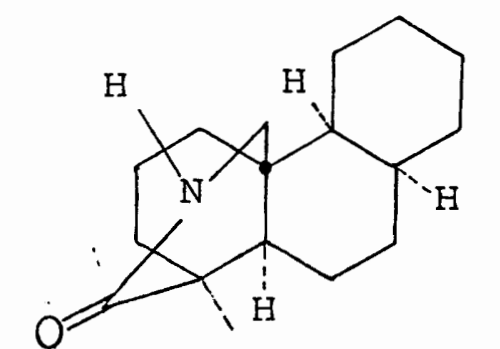

(II)

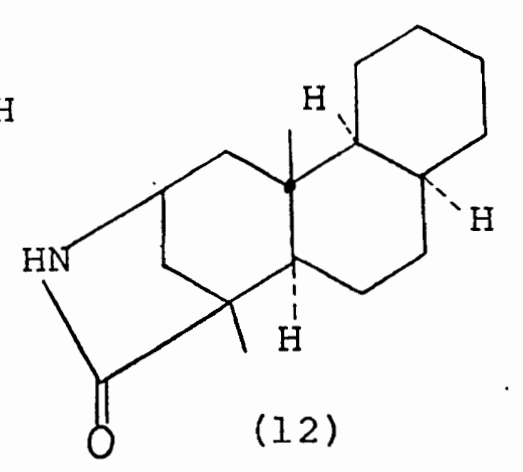


and Edwards also prepared the acyl azide (13) of O-methylpodocarpic acid, and this compound upon photolysis afforded, besides the predominant isocyanate, the $\delta$-lactam (14) in $20 \%$ yield. This result indicated that the buttressing effect of ring $C$ is not essential for $\delta$-lactam formation. A $\gamma$-lactam believed by Apsimon and Edwards to be (15) or (16) was also obtained in 5\% yield. Later work $^{2}$. strongly suggested that the correct structure was (15). Meyer and Levinson ${ }^{3}$ investigated the photolysis of 1,1-dimethyl-trans-decalin-10-carbonyl azide (17). In addition to the corresponding isocyanate, the amide (20) was isolated in $8 \%$ yield along with the $\delta$-lactam (18) in $9 \%$ yield and what is possibly the $\gamma$-lactam (19) in $14 \%$ yield. Although Apsimon and Edwards obtained a high ratio of $\delta$-lactam to $\gamma$-lactam, Meyer and Levinson isolated the $\delta$ - and $\gamma$-lactams in a ratio of 1 to 1.5 . Thus, it would seem that the angular acyl azide group is positioned closer to at least one of its $\gamma$-methylene groups than to the axial methyl group. This conclusion is similar to what Masamune ${ }^{4}$ reported in his synthesis of the $\delta$-lactam (21), a key intermediate for the synthesis of garryine (22). Meyer and Levinson emphasized that the axial hydrogens at 3- and 8-positions are hindered by the axial 1-methyl group. Therefore, the hydrogen at C-6 which suffers no such hindrance is probably more exposed to attack than are the other two.

R.F.C. Brown ${ }^{5}$ photolyzed the cis- and trans-decalin 

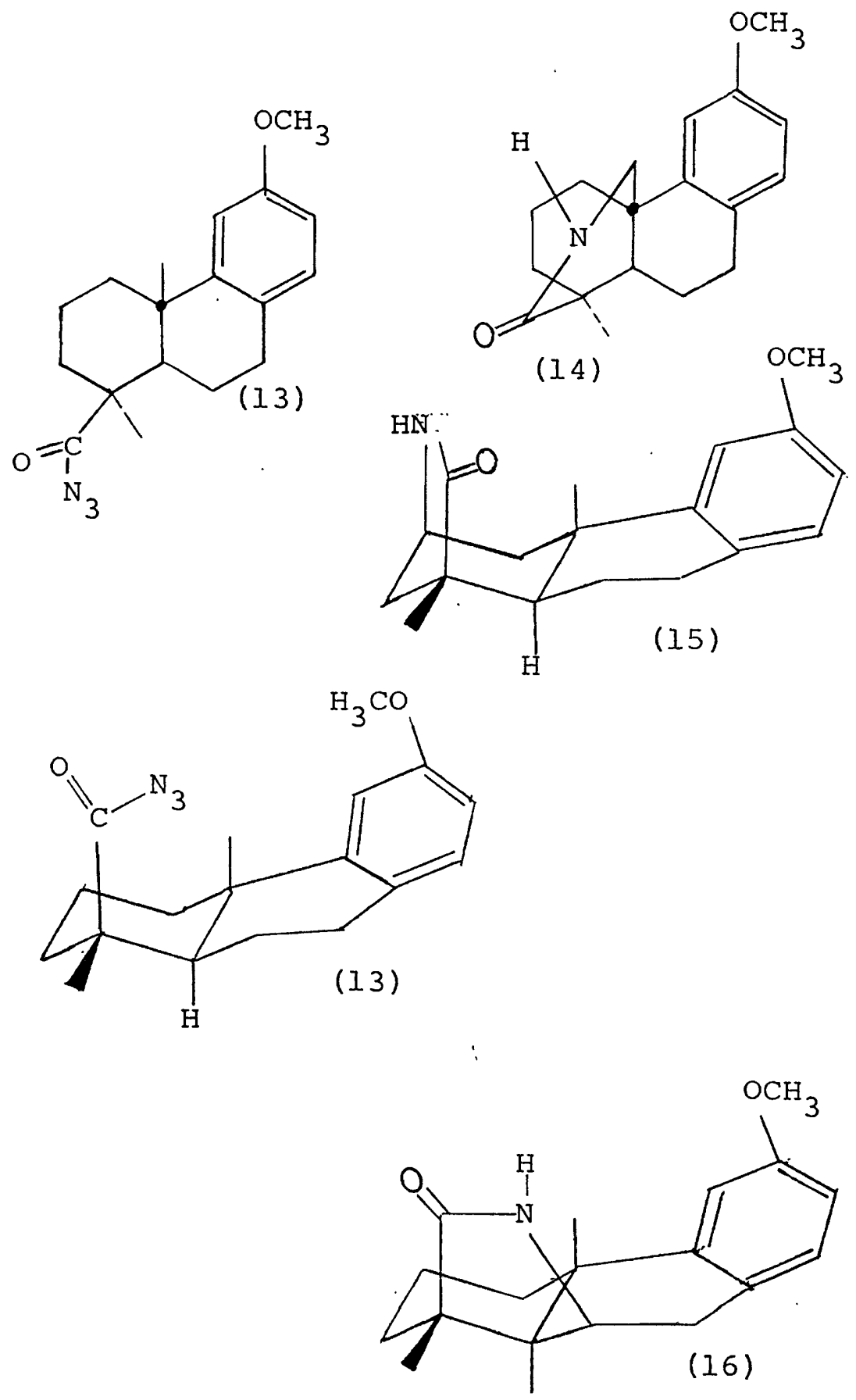

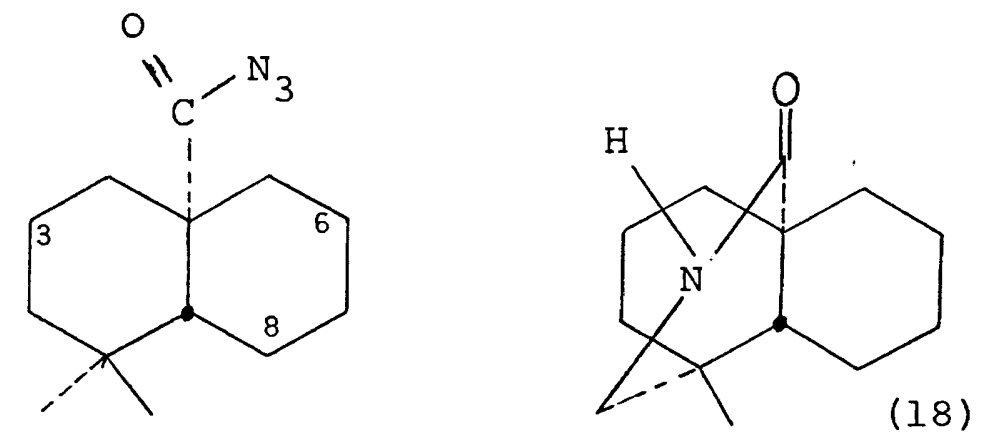

(17) *
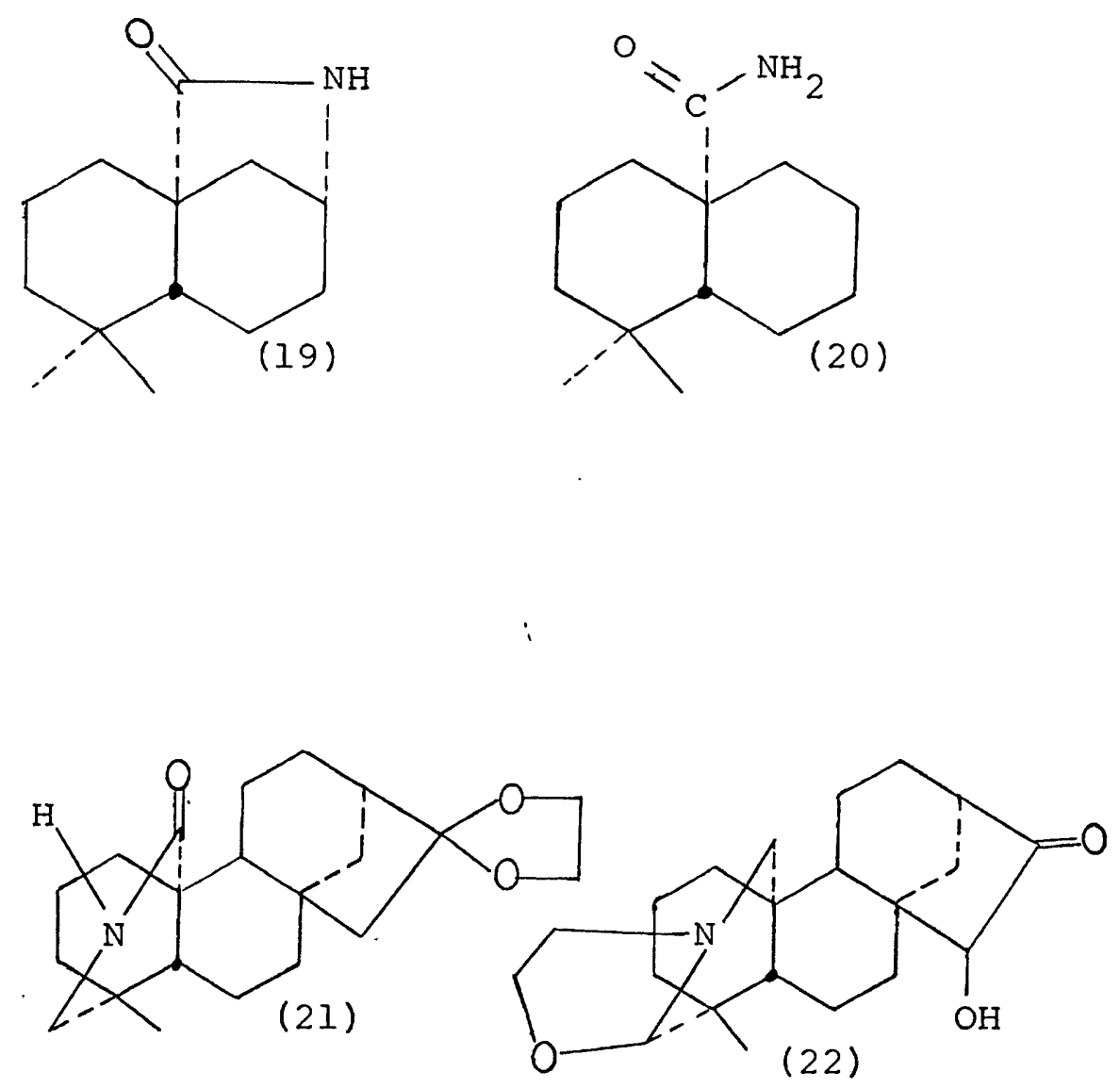

*Synthetic compounds (17-20) are DL-mixtures. 
derivatives (23) and (17). The $\delta$-lactam (24) predominated (18\%) in the case of (23) and the $\delta$-lactam (18) represented only $4 \%$ of the products from (17). (23a) and (23b) are the conformations of the cis-decalin acid azide arising from the flexibility of the cis-decalin system; the preferential formation of the $\delta$-lactam (24) in substantial yield implies that the conformation (23b) must be favored either for the azide or the acyl nitrene species $\mathrm{R}-\mathrm{CO}-\mathrm{N}$, since reaction through conformation (23a) could only lead to a $\gamma$-lactam. (23b) has fewer steric interactions than (23a). In (23b) the acyl nitrene must attack either a methyl group or a ring hydrogen situated 1,3-diaxially to it. There appears to be a preference for attack at the more accessible methyl group, leading to a $\delta$-lactam. Further examples of the use of acyl azide photolysis to synthesize lactams are summerized in Table I.

These data on the synthesis of lactams by acyl azide photolysis allows the following conclusions to be drawn:

1) Both $\gamma$ - and $\delta$-lactams may be formed along with the corresponding amide.

2) The yields of the lactams are generally low and are solvent dependent to some extent. 
TABLE I

EXAMPLES OF ACYL AZIDE PHOTOLYSIS

Azide

(25)

(27)

(29)

(31)

(34)

(36)

(48)

(4I)

(41)

(4I)

\section{Lactam products}

(26) $26 \%$

(28) $9 \%$

(30) $28 \%$

(32) $15 \%$; (33) $15 \%$

(35) $20 \%$

(37) poor yield

(39) $12 \% ;(40) \quad 6 \%$

(39) $21 \% ;(40) \quad 11 \%$

(49) $4.3 \%$

(53) $23 \% ;(54) 11 \%$

(53) $12 \% ;(54) \quad 5 \%$

(53) $13 \%$; (54) $8 \%$

\section{Solvent}

n-Hexane

n-Hexane

cyclohexane

cyclohexane

n-Hexane

n-Hexane

cyclohexane

dichloromethane

dichloromethane

dichloromethane

cyclohexane

cyclohexane
6

\section{Reference}

6

7

8

9

10

$14, \quad 32$

$14, \quad 32$

13

14

14

17 


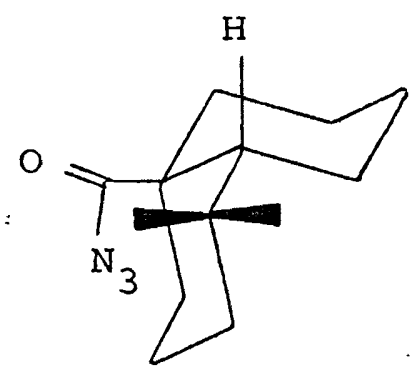

(23)

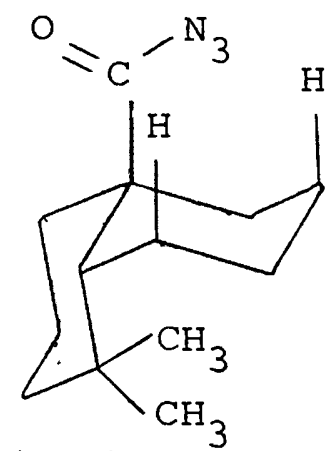

(23a)

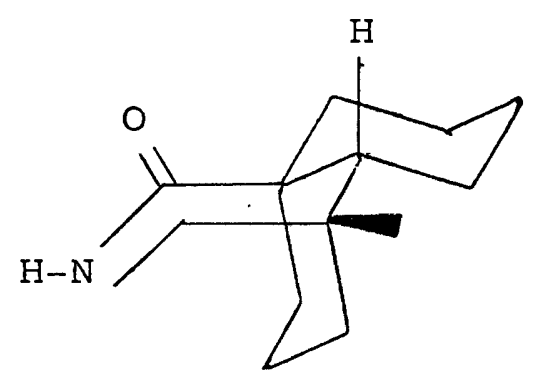

(24)

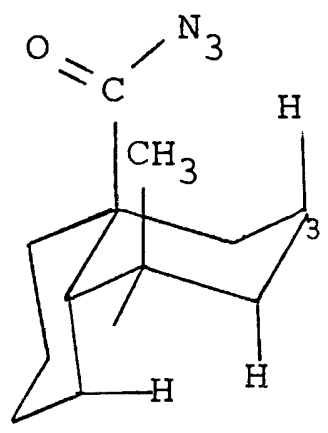

(23b)
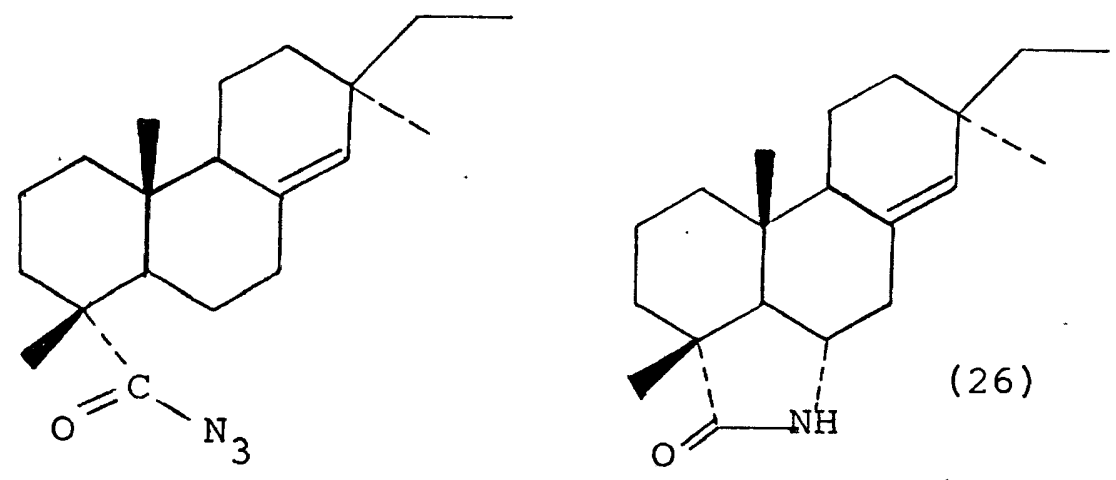

(25) 

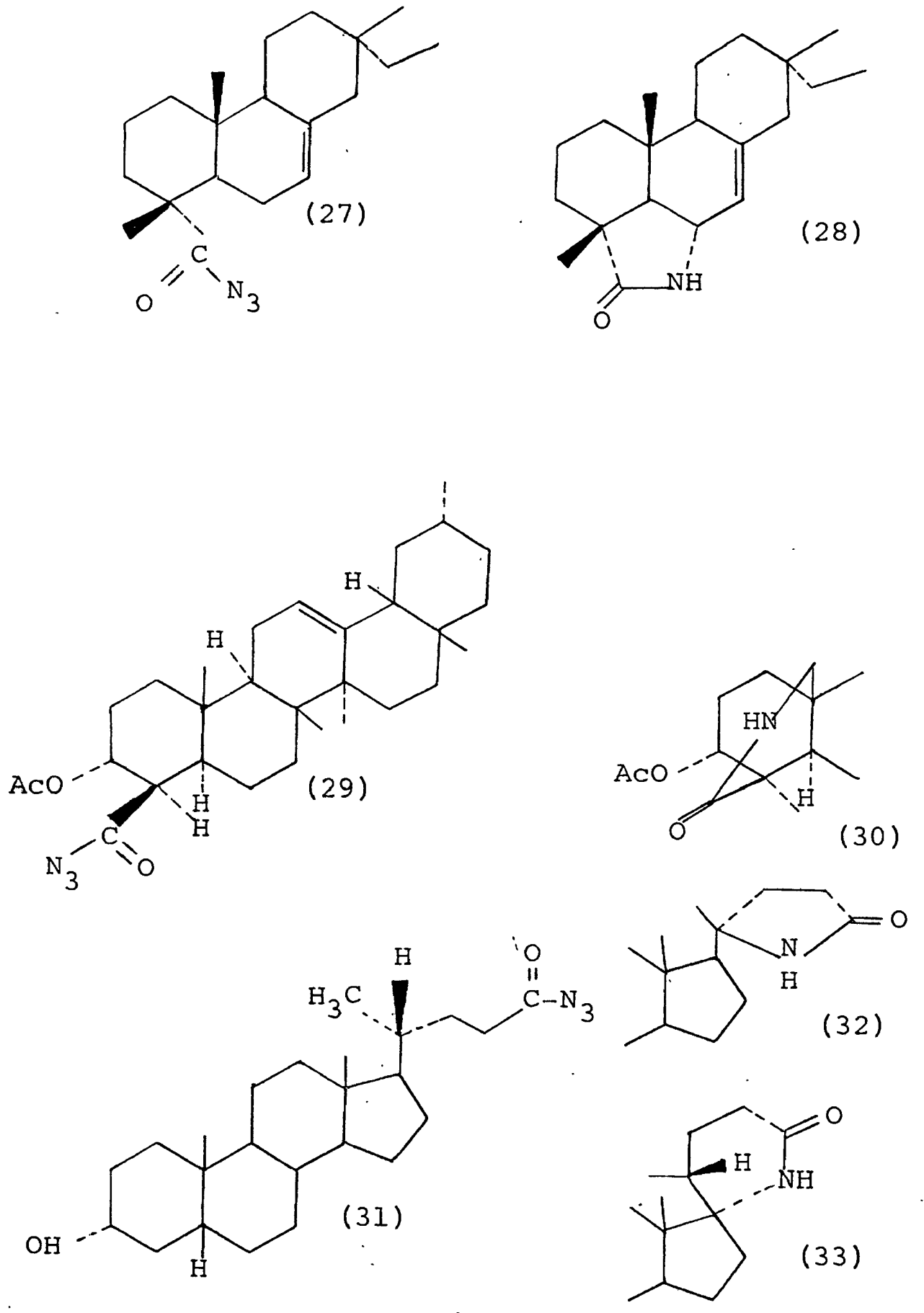

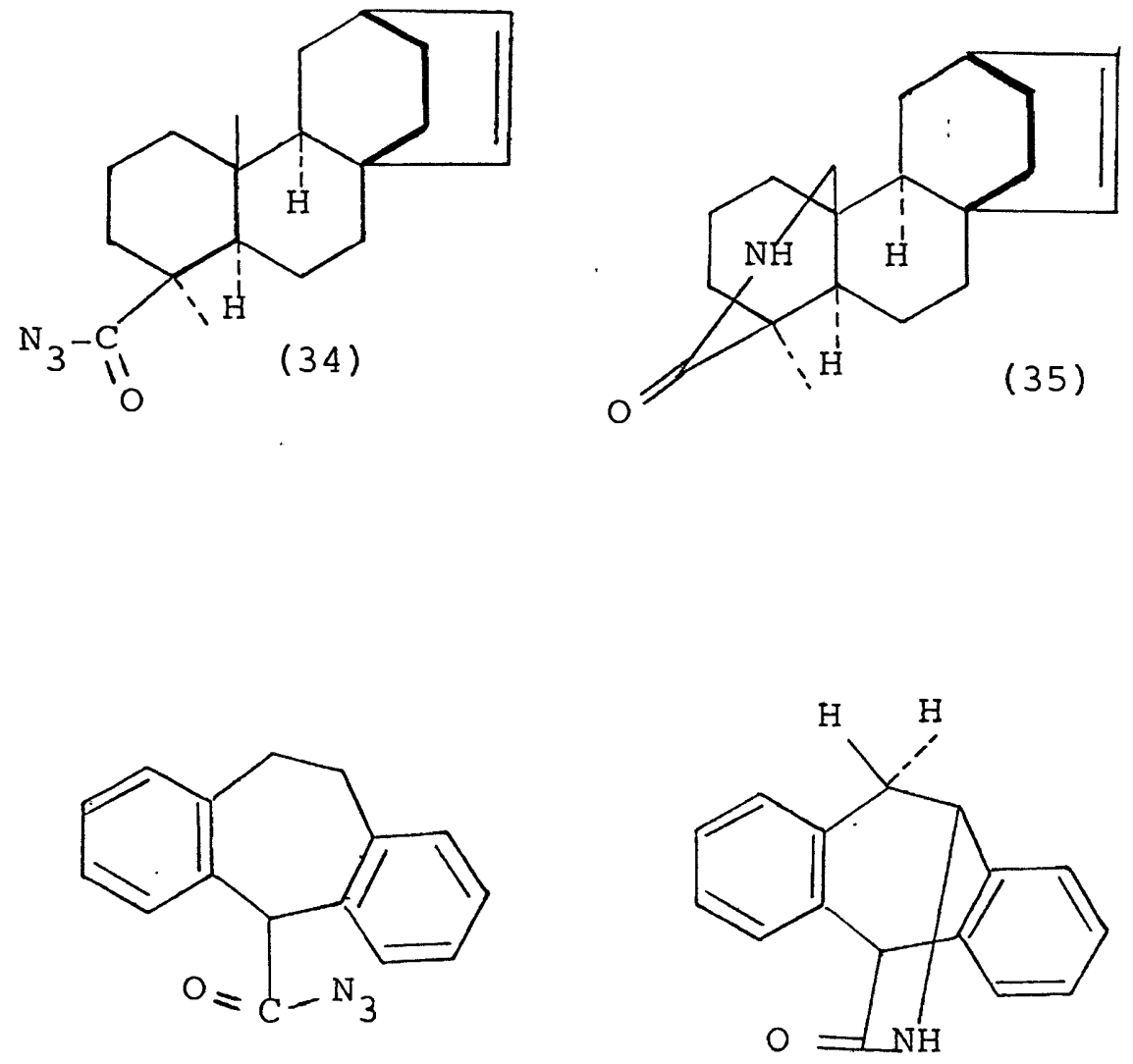

(36)

(37)

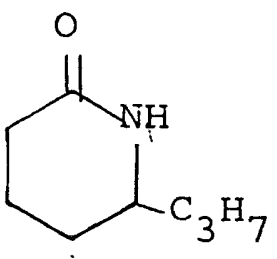

(39)

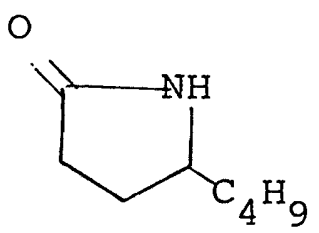

(40)

$\mathrm{CH}_{3}-\left(\mathrm{CH}_{2}\right)_{4} \stackrel{\stackrel{\mathrm{O}}{\|}}{-\mathrm{C}-\mathrm{N}_{3}}$

(4I)<smiles>CC1CCCC(=O)N1</smiles>

(53)

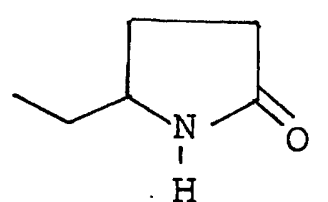

(54) 
The mechanism for this reaction has been studied along with mechanism studies on the photolysis of azidoformates and alkyl azides. A great deal of information relating to these mechanisms is available.

Loss of nitrogen from organic azides.results in most cases in uncharged, electron-deficient molecular fragments containing a nitrogen atom with only six electrons in its valence shell. These reaction intermediates, termed nitrenes, were realistically proposed first for the photochemical decomposition of hydrazoic acid in 1928 by Beckman and Dickinson ${ }^{11}$. In the last 16 years the chemistry in this field has been stimulated by the development of carbene chemistry.

For nitrenes both a singlet state (S) with two pairs of electrons and a low-lying $\mathrm{p}_{\mathrm{x}}$-orbital, and a triplet state (T), with one electron pair and two electrons with parallel spins, are possible.
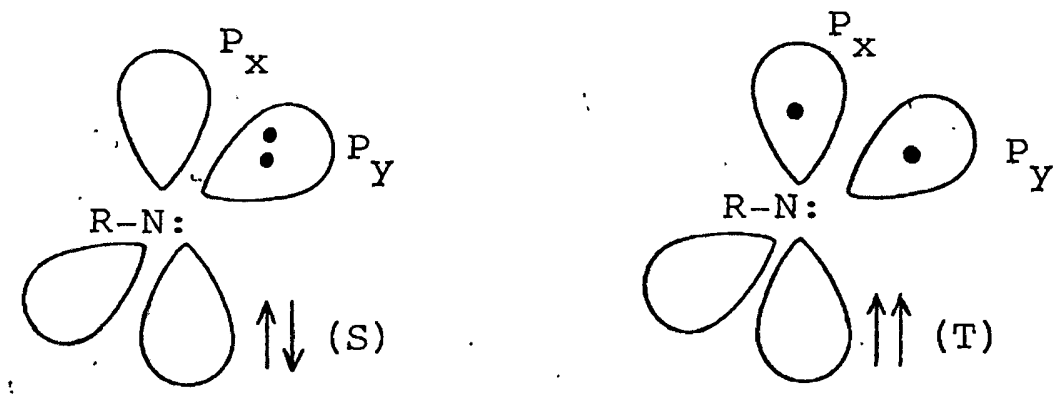

Electron spin resonance (ESR) studies $^{12}$ on a variety of nitrenes generated by photolysis of the corresponding azides at low temperatures ( 4 or $77 \mathrm{~K}$ ) in randomly oriented glasses have indicated in all cases a triplet ground 
state.

The electronic structure of the parent nitrene $\mathrm{NH}$ has been calculated by MO and valence-bond methods. Also, various molecular orbital methods (LCAO-SCF, SCF-MO) have been used to calculate the electronic structure of ground and excited states of nitrenes. The calculations indicate that the ground state is a triplet and the lowest excited state is a singlet (being about $1.76 \mathrm{eV}$ above the ground state). This conclusion applied to all of the nitrenes studied with the exception of carbalkoxynitrenes (ROCON:) for which a definitive statement could not be made.

Evidence has accumulated that singlet nitrenes are the main reacting entities in direct photolysis of acyl azides. This conclusion can be drawn from the work of Smolinsky and Feuer ${ }^{13}$ on azidoformate cyclization. They reported the first examples of retention of optical activity during the insertion of a nitrene into a $\mathrm{C}-\mathrm{H}$ bond at an asymmetric carbon atom. Triplet-state nitrenes would very likely react by abstracting hydrogen atoms, forming separate radicals which eventually coupled. However, a singlet-state nitrene might undergo direct insertion into a $\mathrm{C}-\mathrm{H}$ bond. It is the singlet state which is responsible for the stereospecificity observed during bond formation. An alternative, but less Iikely, explanation for the observed retention of optical activity involved a biradical mechanism in which a triplet state nitrene 
abstracts the hydrogen atom from the asymmetric carbon followed by rapid radical recombination. Also, Yamada and Terashima ${ }^{14}$ studied the photochemical decomposition of the optically active acyl azide (42) in an effort to examine the spin state of the acyl nitrene (which could intervene in lactam formation).

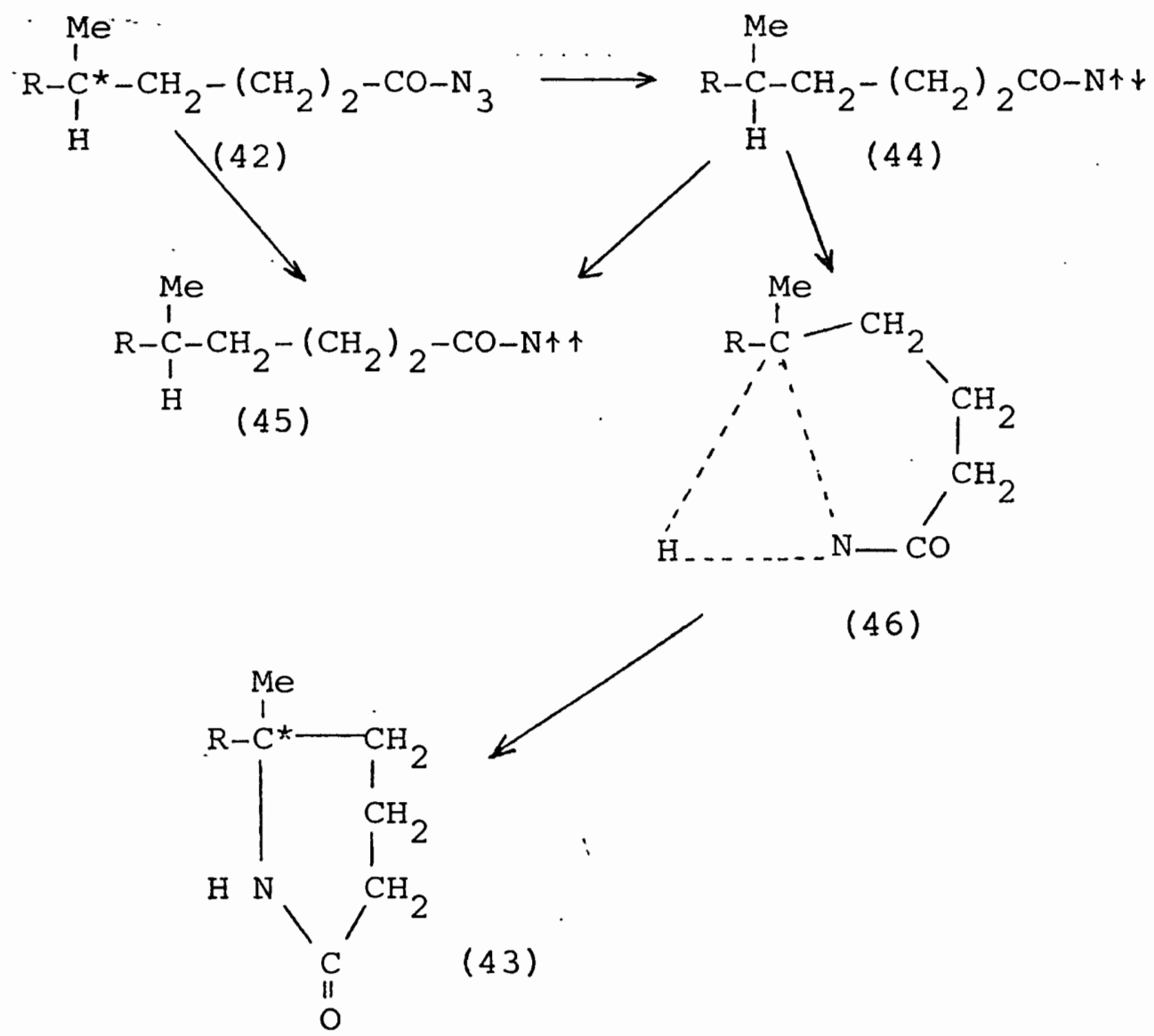

Optically active (R)-5-methyl-6-phenylhexanoyl azide (48) was synthesized from S-(+)-2-methyl-3-phenylpropionic acid (47) and photochemically decomposed in dichloromethane. S-(-)-6-benzyl-6-methyl-2-piperidone (49) was obtained ( $4.3 \%$ ) with $98 \%$ retention of configuration. 


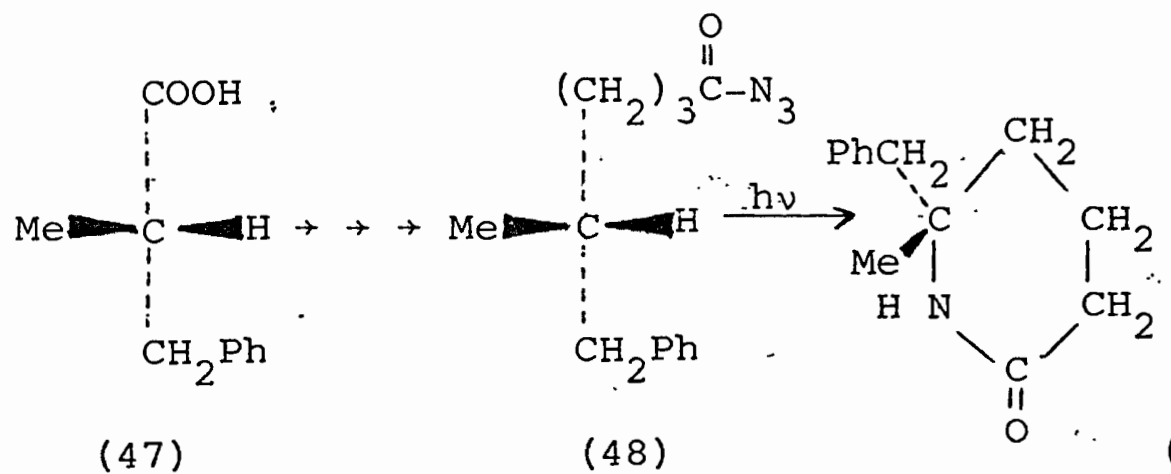

The intramolecular insertion into the optically active $\mathrm{C}-\mathrm{H}$ bond has proceeded with almost $100 \%$ retention of configuration, and lactam (49) was formed most likely from the singlet-state acyl nitrene (44) through transition state. (46, $\mathrm{R}=\mathrm{PhCH}_{2}$ ).

In a review paper $\mathrm{W}$. Lwowski ${ }^{15}$ claimed that nitrene products have been obtained only on photolysis, and not on thermolysis, of alkane- and arenecarboxylic azides. No nitrenes are formed during the thermal Curtius rearrangement; the reaction proceeds in a single step with simultaneous removal of the nitrogen and migration of the alkyl or aryl group:

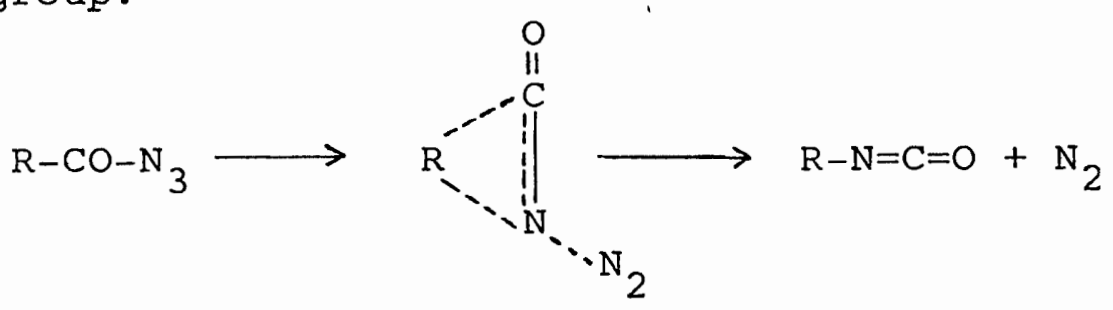

Further studies on the decomposition of acyl azides were pioneered by Tisue and coworkers ${ }^{16}$ in order to investigate the mechanism of the photolytic Curtius rearrangement. They photolyzed pivaloyl azide (50) in cyclohexane 
and isolated $\underline{N}$-cyclohexylpivalamide (51) in $20 \%$ yield and pivalamide (52) in $0.5 \%$.

$$
\left(\mathrm{CH}_{3}\right)_{3} \mathrm{C}-\mathrm{CO} \mathrm{N}{ }_{(50)} \stackrel{\mathrm{h \nu}}{\longrightarrow}\left(\mathrm{CH}_{3}\right)_{3} \mathrm{C}-\mathrm{CO}-\mathrm{N}+\left(\mathrm{CH}_{3}\right)_{3} \mathrm{C}-\mathrm{CO} \mathrm{NH}{ }_{(52)}
$$

Photolysis of $(50)$ in neopentane gave a $13 \%$ yield of isobutylene. Thus, if the pivaloylnitrene was not intercepted, it appeared to decompose into isobutylene and isocyanic acid. The isocyanic acid, together with part of the isobutylene, formed a polymeric oil, whose IR spectrum showed C-H absorption (at $299.4 \mathrm{~cm}^{-1}$ ) as well as $\mathrm{N}-\mathrm{H}$ (broad, about $3290 \mathrm{~cm}^{-1}$ ) and carbonyl absorptions (about $1686 \mathrm{~cm}^{-1}$ ). Including the oil and t-butyl isocyanate, the total yields were always greater than $90 \%$ based on the pivaloyl azide used.

The selectivity of the insertion of pivaloylnitrene into $\mathrm{C}-\mathrm{H}$ bonds was 160:9:1 for the tertiary, secondary and primary $\mathrm{C}-\mathrm{H}$ bonds in 2 -methylbutane. The yield of $t$-butyl isocyanate was always $39-42 \%$, which provided a clue to the mechanism of the rearrangement. If pivaloylnitrene were the precursor of the isocyanate, the quantity of isocyanate obtained should decrease with increasing ability of the solvent to intercept nitrenes. Investigation of the yields obtained using different solvents such as neopentane, cyclopentane and cyclohexene showed that the isocyanate could not have been formed directly from excited pivaloyl 
azide.

Linke and colleagues ${ }^{17}$ determined that pivaloylnitrene, generated photolytically from pivaloyl azide, did not rearrange to: $t$-butyl isocyanate at a detectable rate. They argued that neither singlet nor triplet pivaloylnitrene were intermediates in the thermal or in the photo-induced Curtius rearrangement of pivaloyl azide. Thus, the accumulated data suggested that the photolytic Curtius rearrangement was most likely a concerted process. In order to provide information about factors determining the relative amounts of $\gamma$ - and $\delta$-lactam when both can be formed, hexanoyl azide was photolyzed ${ }^{18}$. Two nearly equivalent methylenes were available for internal attack of the nitrene and no unusual proximity effect was present. Irradiation of a dilute solution of the azide in cyclohexane gave as expected $13 \%$ of $\delta$-lactam (53) and $8 \%$ of $\gamma$-lactam (54). Attack on the solvent afforded $3 \%$ of N-cyclohexylhexanamide (55), the rest of the product being isocyanate. The work of Brown and Edwards showed that if equivalent methylenes were available $\delta$-lactam was favored over $\gamma$-lactam by a ratio of around $2: 1$. This product ratio was interpreted as a consequence of transition state (56) for singlet insertion being favored over (57). This ratio was called the ring-size factor. Thus the singlet state of the acyl nitrene would favor the formation of $\delta$-lactam via $\mathrm{C}-\mathrm{H}$ insertion (transition state 58) whereas triplet state would give $\gamma$-lactam by internal 


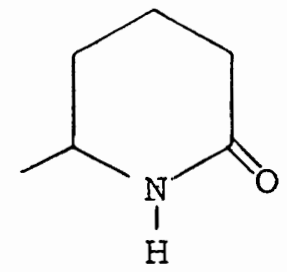

(53)

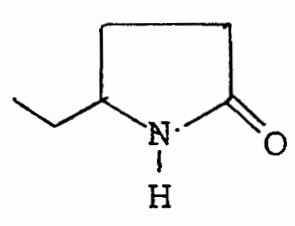

(54)

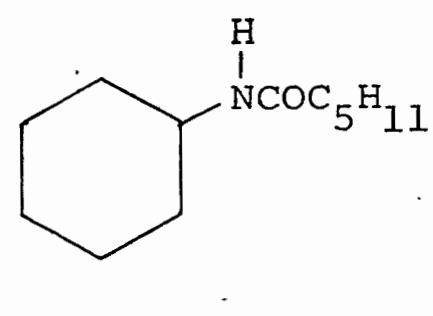

(55)

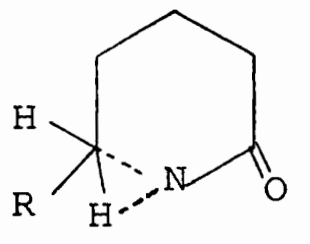

(56)

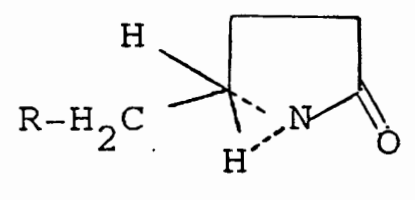

(57)

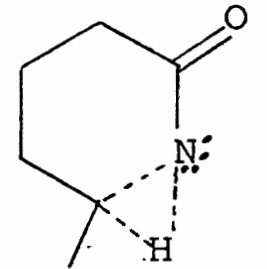

(58)

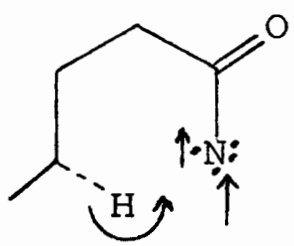

(59) 
hydrogen abstraction (transition state 59). It was concluded that the preferential $\delta$-lactam formation in the hexanoyl azide case was a consequence of the preferred geometry for singlet nitrene insertion into the $\mathrm{C}-\mathrm{H}$ bond (transition state 58).

In the cases of rigid geometry related to podocarpic acid (13), it was found that the ratio of $\delta$ - to $\gamma$-lactam was roughly $4: 1$, mainly because of the proximity of the axial azido-carbonyl and methyl groups.

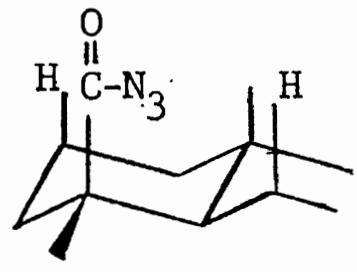

(13)

Examination of the photochemical decomposition of hexanoyl azide in the presence of acetophenone, an efficient triplet sensitizer ${ }^{19}, 20$, gave results in striking contrast to those of the direct photolysis. When a cyclohexane solution of hexanoyl azide and acetophenone was irradiated, $\mathrm{N}_{2}$ was rapidly evolved. Hexanamide crystallized in a $78 \%$ yield. No isocyanate was detectable, but dicyclohexyl and cyclohexene were. GLC failed to disclose the presence of $\delta$-lactam (53) or $\gamma$-lactam (54). It was suggested that the photosensitized decomposition gave products characteristic of radical reactions, and hence of the triplet state of the excited azide or nitrene. Thus, excited nitrenes could be the reactive intermediates. The reactions were formulated as shown in the following 
scheme:

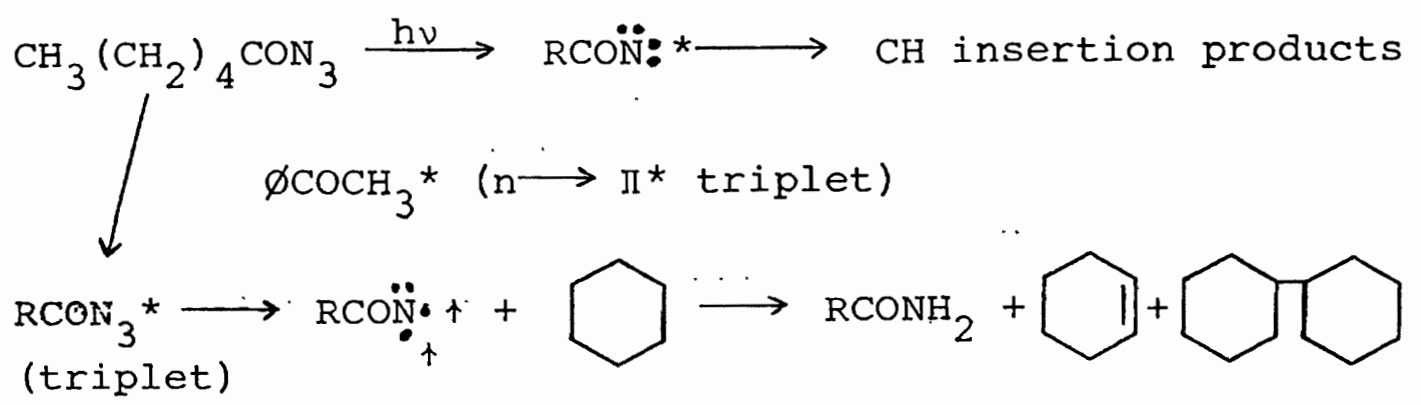

The products from the triplet state could be obtained free from the $\mathrm{CH}$ insertion products by specifically producing the triplet azide by triplet transfer from the photosensitizer acetophenone, thereby bypassing the singlet nitrene.

Felt, Linke and Lwowski ${ }^{21}$ studied the stabilization of the singlet-state of acyl nitrenes by dichloromethane. Solvent interaction speeding up or slowing down the intersystem crossing competes with chemical reactions, and the ratio of singlet derived products to triplet derived products will change. It was found that apparently dichloromethane drastically affeçted both intra- and intermolecular reactions of acyl nitrenes. Photolysis of acyl azides in $\mathrm{CH}_{2} \mathrm{Cl}_{2}$ indicated $\mathrm{C}-\mathrm{H}$ insertion yields twice as high as in cyclohexane. About twice as much $\delta$-lactam as $\gamma$-lactam was formed ${ }^{18}$. . It was concluded that $\mathrm{CH}_{2} \mathrm{Cl}_{2}$ stabilized the insertion-active state of the nitrenes (the singlet) without removing its $\mathrm{C}-\mathrm{H}$ insertion reactivity.

In the case of carbalkoxynitrenes, dilution with an 
inert solvent should result in the initially formed singlet nitrene undergoing an increased amount of intersystem crossing to the ground state triplet. It was found 22 that dilution of cyclohexane with an equal volume of hexafluorobenzene raised the thermal insertion yields to about $76 \%$. This could be explained by the fact that the singlet nitrene might complex with fluorine in $\mathrm{C}_{6}{ }^{\mathrm{F}}{ }_{6}$ to give a nitrenoid-type species which is stable enough to decrease the rate of intersystem crossing but active enough to insert into $\mathrm{C}-\mathrm{H}$ bond of a saturated hydrocarbon.

The effect of dichloromethane on reactions involving nitrenes was pursued by Belloli and his colleagues ${ }^{23}$. There was ample experimental evidence to support the statement that nitrenes, generated from a variety of precursors, could be made to cross from an initially formed singlet state to a lower energy triplet state by collisional deactivation with inert solvent molecules. Collisional deactivation or destabilization of singlet states by inert solvents could mean the actual promotion of intersystem crossing by electronic interactions as with heavy-atom solvents, or simply that the solvent by being inert would allow intramolecular intersystem crossing to compete favorably with reactive collision, or both.

Lwowski demonstrated that dichloromethane acted to stabilize the singlet-state character of a number of acyl nitrenes without removing their $\mathrm{C}-\mathrm{H}$ insertion reactivity ${ }^{21}$. Based on LCAO-MO-SCF calculations, it was concluded that 
singlet-triplet separations in carbalkoxynitrenes might be much smaller than for acyl nitrenes and that this might manifest itself in a reduced tendency of carbalkoxynitrenes to undergo intersystem crossing : $\mathrm{C}_{6} \mathrm{~F}_{6}$ stabilizes singlet carbalkoxynitrenes by the same type of interaction by which $\mathrm{CH}_{2} \mathrm{Cl}_{2}$ stabilizes singlet acyl nitrenes. Dichloromethane has a singlet stabilizing effect on carbalkoxynitrenes as well as on acyl nitrenes.

Some question has existed whether the effect of $\mathrm{C}_{6} \mathrm{~F}_{6}$ is that of singlet stabilizing by complex formation as with $\mathrm{CH}_{2} \mathrm{Cl}_{2}$ or whether it is functioning as a radical trap. For carbethoxynitremes the absolute yield of $\mathrm{C}-\mathrm{H}$ insertion products was shown ${ }^{24}$ to increase dramatically upon initial dilution of the azide-hydrocarbon reaction mixture with $\mathrm{C}_{6} \mathrm{~F}_{6} \cdot$ with an eventual leveling off at high dilution. It was concluded that $\mathrm{CH}_{2} \mathrm{Cl}_{2}$ formed a stronger complex with carbethoxynitrene than $\mathrm{C}_{6} \mathrm{~F}_{6}$, since at high dilution the percent product was substantially less with $\mathrm{CH}_{2} \mathrm{Cl}_{2}$ than with $\mathrm{C}_{6} \mathrm{~F}_{6}$. The stereospecificity data was in accord with many observations that only the singlet carbethoxynitrene inserted into inactivated $\mathrm{C}-\mathrm{H}$ bonds.

It can be concluded that in acyl azide photolysis:

1) Acyl nitrenes are the reactive intermediates (except in the formation of the major product, the isocyanate, by a concerted rearrangement of the azide). 
2) Singlet nitrenes are the main reacting entities, undergoing direct insertion into $\mathrm{C}-\mathrm{H}$ bonds, usually producing a $\delta$-lactam. Solvents like $\mathrm{CH}_{2} \mathrm{Cl}_{2}$ and $\mathrm{C}_{6} \mathrm{~F}_{6}$ increase the yield of insertion products by stabilizing the singlet-state of the acyl nitrene.

3) The singlet state of the azide can undergo intersystem crossing to a triplet state which would yield a $\gamma$-lactam by internal hydrogen abstraction.

4) The ring-size factor and the proximity effect are important in determining the relative yields of $\gamma$ - and $\delta$-lactam. 


\section{CHAPTER III}

\section{DISCUSSION}

1-phenylcyclohexaneacetic acid (60) was chosen as the starting material for the synthesis of 3-oxo-5-phenylmorphan (6). The introduction of the required nitrogen atom was carried out by conversion of the carboxylic acid (60) to the corresponding acyl azide (1) as follows: Treatment of the acid (60) with thionyl chloride ${ }^{25}$ afforded the acid chloride (61) in $87 \%$ yield. The infrared spectrum. of a thin film of (61) showed the appropriate carbonyl stretching $\left(1810 \mathrm{~cm}^{-1}\right.$ ) and bending frequencies (995 and $930 \mathrm{~cm}^{-1}, 26,27$. An n.m.r. spectrum of a purified sample of (6I) taken in deuterochloroform $\left(\mathrm{CDCl}_{3}\right)$ showed a singlet at $3.10 \mathrm{ppm}$ assigned to the methylene protons adjacent to . the carbonyl. The ten protons of the cyclohexane ring had chemical shifts at $1.46,1.8$ and $2.12 \mathrm{ppm}$; whereas the five phenyl protons were shown as a multiplet around $7.25 \mathrm{ppm}$.

The acid chloride (61) was converted to the acyl azide (5) by treatment with an aqueous solution of sodium azide in dioxane 28 . The infrared spectrum of the isolated azide (5) exhibited an intense band at $2130 \mathrm{~cm}^{-1}$ due to the asymmetric stretching vibration of the $-\mathrm{N}_{3}$ group $26,27$. 


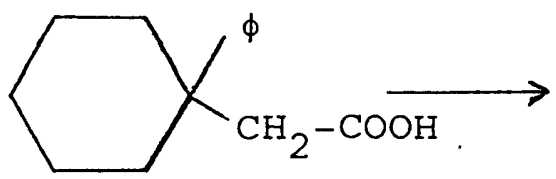

(60)

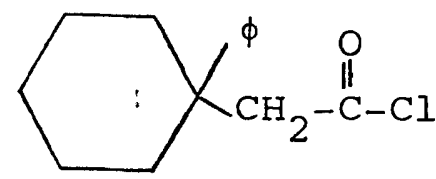

(6I)

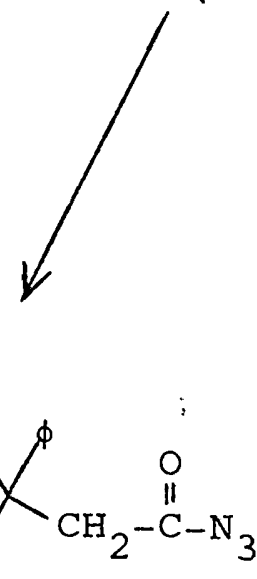

(5)

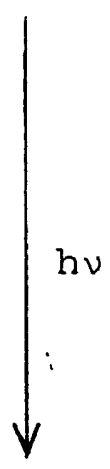

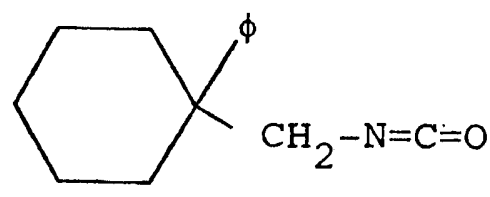

(62)

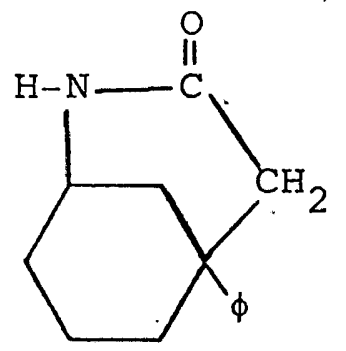

(6) 
A much less intense $\left(-\mathrm{N}_{3}\right)$ symmetric band occurred at 1320 $\mathrm{cm}^{-1}$. The carbonyl absorption at $1714 \mathrm{~cm}^{-1}$ confirmed the structure of the azide (5). The yield of (5) was not determined and its n.m.r. spectrum was not taken due to its thermal instability. Attempts to prepare the azide by using ether as a solvent ${ }^{16}$ instead of dioxane resulted in much slower rates of formation of the product; the reaction was monitored by observing the disappearance of acid chloride carbonyl absorption at $1810 \mathrm{~cm}^{-1}$ and the relative intensity of the azide ( $C=0)$ absorption at 1714 $\mathrm{cm}^{-1}$. Another trial to prepare the azide by reacting the acid chloride with sodium azide in DMSO failed due to emulsification ${ }^{5}$.

The photolysis of l-phenylcyclohexaneacetic acid azide (5) was carried out in $\underline{n}$-hexane. The infrared spectrum of the crude photolysate showed an intense band at $2260 \mathrm{~cm}^{-1}$, indicating the rearrangement of the azide to the corresponding isocyanate, and two less intense bands in the carbonyl region at 1714 and $1680 \mathrm{~cm}^{-1}$. (The reaction was also run in dichloromethane, but the carbonyl absorption at $1680 \mathrm{~cm}^{-1}$ was almost absent in the IR of the crude mixture indicating that no appreciable amidic product was formed.) Thin layer chromatography of the crude mixture was performed using several developing solvent systems (e.g., acetone/chloroform, benzene/ether, benzene/methanol/ acetic acid) but the best results were obtained with 
dichloromethane/ethyl acetate (1:1). Three spots were detected under UV light with $R_{f}$ values $0.36,0.49$ and 0.77 .

High pressure liquid chromatography and column chromatography were the two main techniques used to isolate the products of the photolysis. The two methods provided a white solid (m.p., 167.5-168 ${ }^{\circ} \mathrm{C}$ ) whose IR in chloroform showed a single band at $3450 \mathrm{~cm}^{-1}$, corresponding to the $\mathrm{NH}$ stretching frequency of a secondary amide $26,27,29$. Furthermore, the carbonyl band at $1665 \mathrm{~cm}^{-1}$ verified the identity of an amide. An IR of a mineral oil mull of this solid showed also the $\mathrm{NH}$ stretching at $3350 \mathrm{~cm}^{-1}$ and the carbonyl band at $1645 \mathrm{~cm}^{-1}$, suggesting an amide group. But the absence of an amide II band ( $\mathrm{NH}$ deformation) in the 1570-1515 $\mathrm{cm}^{-1}$ region made a lactam seem more likely. Thus the $\delta$-lactam (6), as anticipated, appears to have been formed from the cyclization of the acyl, nitrene intermediate (7) through the triangular transition state (64) by insertion into $\mathrm{C}_{5}-\mathrm{H}$ or $\mathrm{C}_{7}^{-\mathrm{H}:}$

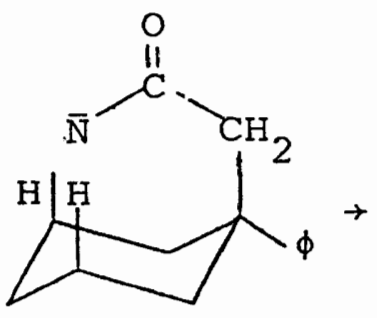

(7)

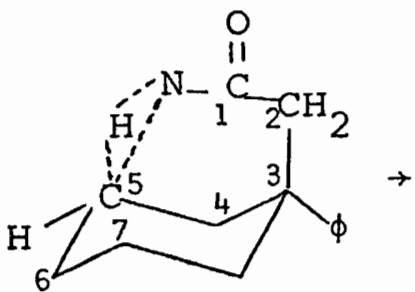

(64)

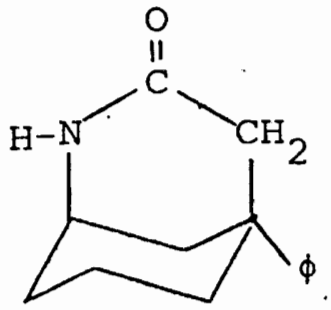

(6) 
Examination of the n.m.r. spectrum of a sample of (6) in $\mathrm{CDCl}_{3}$ revealed a distribution of protons in accord with the above structure (6). The cyclohexyl protons gave complex peaks at $1.48-1.6 \mathrm{ppm}(6 \mathrm{H})$ and at $1.97-2.14 \mathrm{ppm}(2 \mathrm{H})$. The nonequivalent nature of the two methylene protons adjacent to the carbonyl group (3.14 and $3.18 \mathrm{ppm}$ ) should not be surprising in view of the rigidity and lack of symmetry of (6). The difference in chemical shift between those two protons could be partly due to the anisotropic effect exerted by the nearby phenyl group and by the carbonyl double bond 29,30 . The methine proton adjacent to the nitrogen atom exhibited a broad absorption centered at $3.86 \mathrm{ppm}$. The phenyl protons had a chemical shift around $7.28 \mathrm{ppm}$. The only resonance that was obscure was that of the proton on the nitrogen $(-\mathrm{NH}-)$ : the integrator accounted for the presence of six protons under the phenyl peak. Thus it would be suspected that the broad peak for the $\mathrm{NH}$-proton could be lying under that region occupied by the phenyl protons. (Broad lines are frequently observed ${ }^{30}$ for $\mathrm{NH}$-protons because ${ }^{14} \mathrm{~N}$ has a nuclear spin and acts like an electric quadrupole. The proton attached to the nitrogen has the opportunity of seeing the ${ }^{14} \mathrm{~N}$ nucleus in an average of the several possible magnetic quantum states which are available to it. Therefore the broadening of the $\mathrm{NH}$ resonance is due to quadrupole relaxation.) Based on the IR and n.m.r. spectra, it was strongly suggested that the lactam (6) was produced from the photolysis. 
Higher yields of (6) were expected from the Photolysis of the azide (5) in dichloromethane. Unfortunately this was not the case. The yields were much higher when the reaction was run in hexane $(13-14 \%)$. It could be: possible that the singlet destabilization by the external heavy atom effect of dichloromethane was counterbalanced by singlet stabilization due to an interaction between the acyl nitrene and the lone pair electrons of dichloromethane. A similar situation has been observed recently by Takeuchi and coworkers ${ }^{31}$ who studied the stabilization of singlet ethoxycarbonylnitrene.

The major product isolated from the crude photolysis mixture was the isocyanate (62) in about $40 \%$ yield. The infrared spectrum showed a very intense absorption aue to the asymmetric $(-\mathrm{N}=\mathrm{C}=0)$ stretching vibration ${ }^{25}$ at $2260 \mathrm{~cm}^{-1}$. The n.m.r. spectrum confirmed the structure (62): the cyclohexyl protons resonated in the $1.48-2.14 \mathrm{ppm}$ region; the singlet at $3.25 \mathrm{ppm}$ was ascribed to the two protons adjacent to the $-\mathrm{N}=\mathrm{C}=\mathrm{O}$ group and the five phenyi protons had a peak centered around $7.28 \mathrm{ppm}$. The isocyanate (62) was most likely formed, as discussed previously, by the rearrangement of the azide:

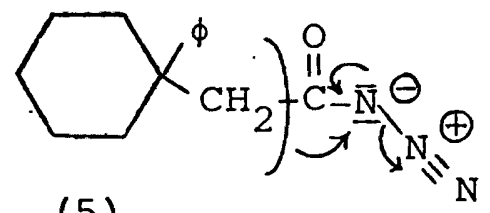

(5)

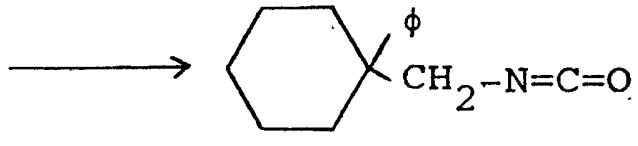

(62) 
It should be noted that (62) was isolated by column chromatography on silica gel and not by HPLC, since it would have reacted with the mobile phase, methanol/water, to produce the corresponding carbamate (63):

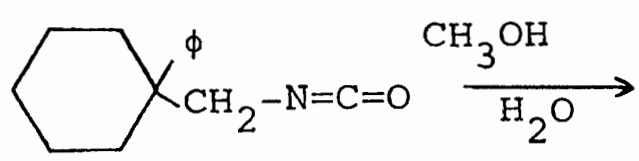

(62)

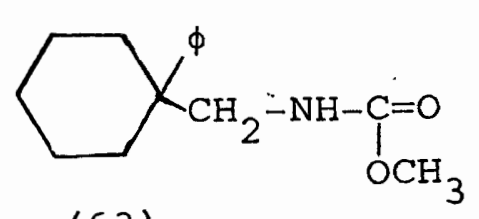

(63)

Finally, another product was detected in the IR of the crude photolysis mixture. It showed a carbonyl absorption at $1714 \mathrm{~cm}^{-1}$. No attempts were exerted to isolate this oily product in a pure form in order to determine its structure. 
CHAPTER IV

\section{EXPERIMENTAL}

\section{GENERAL}

Infrared spectra were recorded on a Perkin-Elmer 467 grating spectrophotometer. N.m.r. spectra were obtained from dilute solutions using a Varian EM 390-90 Mhz spectrometer. Tetramethylsilane was used as an internal standard with deuterochloroform solutions. Gas chromatograms were run on a Hewlett-Packard 5750 Research Chromatograph equipped with a flame ionization detector using nitrogen as the carrier gas. A $5 \%, \mathrm{SE}-30$ column lon Anakrom ABS $100 / 110$ mesh, 6' $6^{\prime} 1 / 8^{\prime \prime)}$ was used: The composition of mixtures was determined by measuring the ratios of the individual peak areas. High pressure liquid chromatography was performed with a Waters Associates Model 440 using an ultraviolet detector $(254 \mathrm{~nm})$. The preparative reverse-phase column Partisil M 9 10/50 ODS and the analytical $\mu$ C-18 column were used. Melting points were taken on a microscope hot stage or by the capillary method with a Buchi Melting Point Apparatus depending on the quantity of material available. The melting points are not corrected. 
l-Phenylcyclohexaneacetyl chloride

The method of Bachmann and Fornefeld ${ }^{25}$ was used. 1-Phenylcyclohexaneacetic acid* (6.51 g; 0.0298 mole) was refluxed gently with freshly distilled thionyl chloride $(25 \mathrm{ml})$ for two hours. The excess thionyl chloride was then removed in vacuo, yielding a yellow oil which was further purified by vacuum distillation (Table II). The colorless** acid chloride showed infrared absorptions at 1810, 995 and $930 \mathrm{~cm}^{-1}$; n.m.r. (cyclohexyl) 1.46, 1.8 and $2.12 \delta ;\left(-\mathrm{CH}_{2}-\mathrm{CO}-\mathrm{Cl}\right) 3.10 \delta$, singlet; and (phenyl) $7.25 \delta$ The yield was $87 \%(6.15 \mathrm{~g})$.

\section{TABLE II}

PRODUCT DATA FOR THREE PREPARATIONS OF 1-PHENYLCYCLOHEXANEACETYL

\section{CHLORIDE}

Weight

of

Acid

$3.07 \mathrm{~g}$

$6.52 \mathrm{~g}$

$6.51: 9$
Weight of

Acid

Chloride

$2.61 \mathrm{~g}$

$5.07 \mathrm{~g}$

$6.15 \mathrm{~g}$

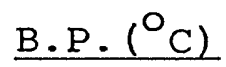

$98-99^{\circ}$

$136 \div 137^{\circ}$

$97-98.5^{\circ}$
Pressure (mm Hq) Yield

$0.1 \mathrm{~mm}$ $78 \%$ $72 \%$

$87 \%$

*I am grateful to Dr. A.S. Levinson for supplying the acid utilized in this research.

**Even though the acid chloride distilled either as a colorless or pale yellow oil, the pale yellow color was discharged on standing. 
1-Phenylcyclohexaneacetic acid azide

A typical experiment is described by J.B. Nabors and coworkers ${ }^{28}$. This reaction was carried out 14 times with comparable results.

1-Phenylcyclohexaneacetyl chloride (1.03 g; 0.00437 mole) was dissolved in dioxane $(20 \mathrm{ml})$ to which a chilled aqueous solution of sodium azide ( $1.88 \mathrm{~g} \mathrm{NaN}_{3}$ in $8 \mathrm{ml} \mathrm{H}_{2} \mathrm{O}$ ) was added all at once. The solution was then extracted three times with $25 \mathrm{ml}$-portions of cold hexane, and the hexane extracts were dried over calcium chloride (5 g; mesh 8) at $-10^{\circ} \mathrm{C}$ for two hours. An aliquot taken for IR (after evaporation of hexane on the salt plates) established the presence of the acyl azide functional group $\left(v-\mathrm{N}_{3}\right.$ : $2130 \mathrm{~cm}^{-1} ; \mathrm{v}-\mathrm{CH}: 2930 \mathrm{~cm}^{-1} ; \nu-\mathrm{C}=0: 1714 \mathrm{~cm}^{-1}$ ).

Photolysis of 1-phenylcyclohexaneacetic acid azide

The reaction solvent, freshly distilled $\underline{n}$-hexane $(A R ; 250 \mathrm{ml})$, introduced into the l-liter cell of the apparatus* (Figure 1) was warmed over a hot plate (set on low) for 10 minutes; then a gentle stream of nitrogen was bubbled through the solvent for one hour to displace any oxygen present. A 450-watt mercury lamp (Hanovia Type 679A36) was inserted inside the $250 \mathrm{ml}$ quartz finger. The solvent was brought to a temperature of $12^{\circ} \mathrm{C}$ by use of cold water in the jacket and an ice-water bath.

*The apparatus was installed in the hood provided with sliding glass windows covered with aluminum foil. 


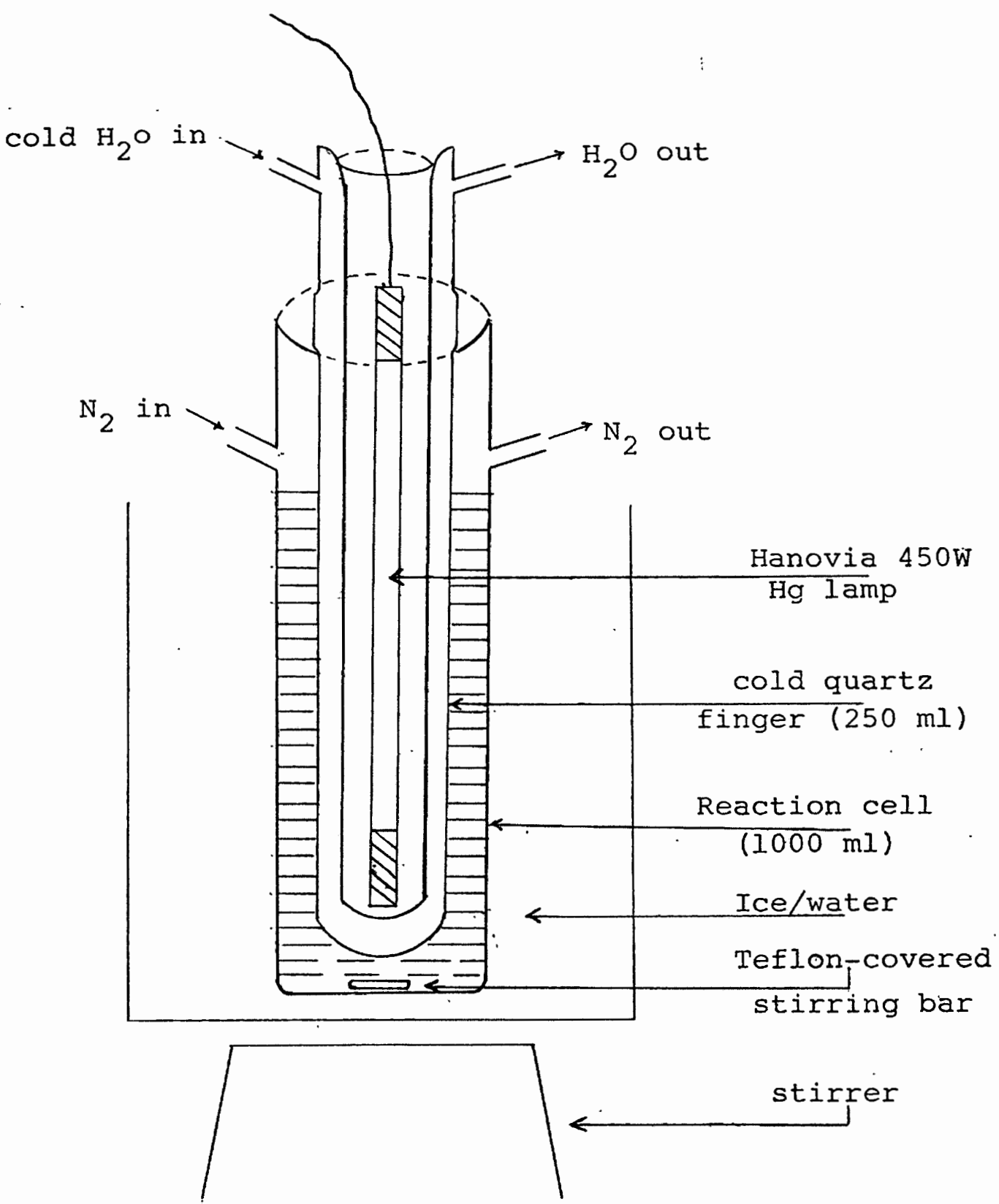

Fiqure 1 Photolysis apparatus 
The cold azide solution was decanted into the reaction cell. Then $70 \mathrm{ml}$ of cold hexane was added to rinse the walls of the apparatus and $\mathrm{N}_{2}$ was bubbled vigorously through the solution for 15 minutes. The dilute acyl azide solution was irradiated for one hour. The temperature of the cell rose to $18^{\circ}$ during the first 15 minutes of the reaction and remained constant thereafter. The progress of the reaction was followed by taking IR spectra of aliquots. The disappearance of the azide absorptions ( $\nu_{\max }: 2130$ and $1714 \mathrm{~cm}^{-1}$ ) and the formation of the isocyanate ( $\nu_{\max }$ $1680 \mathrm{~cm}^{-1}$ ) indicated the completion of the reaction. A light brown solid (ca. $20 \mathrm{mg}$ ) deposited on the walls of the quartz finger. The solution was filtered and concentrated by removal of hexane on a rotating evaporator with a warm water bath and an aspirator vacuum. The resulting caramel brown oil (0.62 g) from $1.03 \mathrm{~g}$ of acid chloride showed two sharp IR absorptions in the carbonyl region ( ${ }_{\max }^{\operatorname{cap}}: 1714$ and $1680 \mathrm{~cm}^{-1}$ ).

When dichloromethane was used as the major photolysis solvent, the crude reaction products showed a broad carbonyl absorption with a maximum at $v: 1710 \mathrm{~cm}^{-1}$ (Table III).*

* The acyl azide solution of the above photolyses was usually irradiated with the $450 \mathrm{~W}$ Hanovia lamp except in the first and 14th photolysis where the $100 \mathrm{~W}$ lamp was used. 


\section{TABLE III}

\section{GENERAL PHOTOLYSIS CONDITIONS, \\ IR CARBONYL ABSORPTIONS AND \\ METHODS OF SEPARATION OF THE CRUDE MIXTURE}

\begin{tabular}{|c|c|c|c|c|c|}
\hline $\begin{array}{l}\text { Photo- } \\
\text { lysis }\end{array}$ & Solvent & Time (hr). & $\begin{array}{l}\text { ature } \\
\left({ }^{\circ} \mathrm{C}\right)\end{array}$ & $\operatorname{IR}(C=0)$ & $\begin{array}{l}\text { Separa- } \\
\text { tion* }\end{array}$ \\
\hline I & $\mathrm{CH}_{2} \mathrm{Cl}_{2}$ & 6 & $12^{\circ}$ & $1725 \mathrm{~cm}^{-1}$ & - \\
\hline II & $\mathrm{CH}_{2} \mathrm{Cl}_{2}$ & 11 & $10-11^{\circ}$ & $1708 \mathrm{~cm}^{-1}$ & - \\
\hline III & $\mathrm{CH}_{2} \mathrm{Cl}$ & 9 & $11^{\circ}$ & $1708 \mathrm{~cm}^{-1}$ & - \\
\hline IV & $\mathrm{CH}_{2} \mathrm{Cl}_{2}$ & $9-3 / 4$ & $8-8.5^{\circ}$ & $1705 \& 1725 \mathrm{~cm}^{-1}$ & C \\
\hline $\mathrm{V}$ & $\mathrm{CH}_{2} \mathrm{Cl}_{2}$ & $6-1 / 2$ & $9-10^{\circ}$ & $1700 \& 1725 \mathrm{~cm}^{-1}$ & $\mathrm{C}$ \\
\hline VI & $\mathrm{CH}_{2} \mathrm{Cl}_{2}$ & $9-1 / 2$ & $11^{\circ}$ & $1700 \& 1725 \mathrm{~cm}^{-1}$ & $D$ \\
\hline VII & $\mathrm{CH}_{2} \mathrm{Cl}_{2}$ & $6-1 / 2$ & $11^{\circ}$ & $1725 \& 1685 \mathrm{~cm}^{-1}$ & $D$ \\
\hline VIII & $\begin{array}{l}\mathrm{CH}_{2} \mathrm{Cl}_{2}{ }^{\prime} \\
\text { Hexane }(4: 1)\end{array}$ & 8 & $12.5^{\circ}$ & $1710-1680$ & $\mathrm{C}$ \\
\hline IX & $\begin{array}{l}\mathrm{CH}_{2} \mathrm{Cl}_{2}{ }^{\prime} \\
\text { Hexane }(4: 1)\end{array}$ & $8-1 / 2$ & $13^{\circ}$ & $1710-1680$ & $\mathrm{C}$ \\
\hline$x$ & $\begin{array}{l}\mathrm{CH}_{2} \mathrm{Cl}_{2} / \\
\text { Hexane }(3: 1)\end{array}$ & $4-1 / 2$ & $12^{\circ}$ & $1725-1670$ & . $E$ \\
\hline$X I$ & $\begin{array}{l}\mathrm{CH}_{2} \mathrm{Cl}_{2} \mathrm{~J} \\
\text { Hexane }(3: 1)\end{array}$ & 2 & $: 11^{\circ}$ & $1725-1670$ & $A$ \\
\hline XII & $\begin{array}{l}\mathrm{CH}_{2} \mathrm{Cl}_{2} \mathrm{l} \\
\text { Hexane }(3: 1)\end{array}$ & $1-1 / 2$ & $11^{\circ}$ & $1725-1670$ & A \\
\hline XIII & $\begin{array}{l}\mathrm{CH}_{2} \mathrm{Cl}_{2} / \\
\text { Hexane }(9: 1)\end{array}$ & $1-1 / 4$ & $12-18^{\circ}$ & $1725-1670$ & - \\
\hline$X I V$ & $\mathrm{CH}_{2} \mathrm{Cl}_{2}$ & 4 & $13-15^{\circ}$ & $1710-1680$ & - \\
\hline $\mathrm{XV}$ & $\underline{n}$-Hexane & 1 & $13-18^{\circ}$ & $1714 \& 1680$ & A, B \\
\hline XVI & $\underline{n}$-Hexane & 1 & $13-18^{\circ}$ & $1714 \& 1680$ & $A, B$ \\
\hline XVII & $\underline{\text { n-Hexane }}$ & 1 & $17-22^{\circ}$ & $1714 \& 1680$ & $A, B, D$ \\
\hline
\end{tabular}


TABLE III (cont'd)

\begin{tabular}{|c|c|c|c|c|c|c|}
\hline XVIII & $\underline{n}$-Hexane & 1 & $14-19^{\circ}$ & 1714 & $\& 1680$ & $A, B$ \\
\hline XIX & $\underline{n}$-Hexane & 1 & $15-20^{\circ}$ & 1714 & $\& 1680$ & $A, B, D$ \\
\hline $\mathrm{XX}$ & $\underline{n}$-Hexane & 2 & $8-12^{\circ}$ & 1714 & $\& \quad 1680$ & $B$ \\
\hline
\end{tabular}

*The following methods were employed to separate the crude mixture: A: High pressure liquid chromatography (HPLC) B: Column chromatography on silica gel Woelm $(0.05-0.20 \mathrm{~mm})$ C: Column chromatography on alumina (Woelm neutral)

$\mathrm{D}$ : Crystallization of product on standing in $\mathrm{CH}_{2} \mathrm{Cl}_{2}$

E: Medium pressure liquid chromatography.

Gas Iiquid chromatographic analysis of the crude brown oil ( $5 \% \mathrm{SE}-30$ at $160^{\circ}$ and a flow rate of $30 \mathrm{ml} \mathrm{N}_{2} /$ minute) showed three major components with retention times of three, 6.5 and 16 minutes in a ratio of $1: 30: 5$.

Thin layer chromatography of the oily mixture on silica gel (IB-F), using $\mathrm{CH}_{2} \mathrm{CI}_{2} / \mathrm{EtOAC}$ (I:I) as the developing solvent system gave three spots under UV light with $R_{f}$ values** of $0.36,0.49$ and 0.77 , respectively.

Four different techniques, were tried to resolve the photolysis mixture. High pressure liquid chromatography (reverse-phase preparative Partisil M9; mobile phase: $80 \%$ $\mathrm{CH}_{3} \mathrm{OH} / \mathrm{H}_{2} \mathrm{O}$; pressure: $3000 \mathrm{psi}$; flow rate: $3 \mathrm{ml} / \mathrm{min}$.) resolved a portion of the oily mixture $(0.147 \mathrm{~g})$ into four

* Only two spots were obtained for the crude products resulting from the photolysis in $\mathrm{CH}_{2} \mathrm{Cl}_{2}\left(\mathrm{R}_{f^{\prime}} 0.49\right.$ and 0.73$)$. 1 -Phenylcyclohexylacetamide had an $R_{f}$ of 0.32 under the same conditions. 
main components with retention times * of $10,11,13.5$ and 14.5 minutes. The four components were collected as six fractions; then each fraction was extracted twice with $15 \mathrm{ml}$ portions of dichloromethane. Only two fractions, the third (yellow. oil, $0.0991 \mathrm{~g} ; \mathrm{IR}: v_{\max } 3450,3350$, $1720 \mathrm{~cm}^{-1}$ ) and the sixth (white crystals contaminated with oil, $0.0270 \mathrm{~g} ; \mathrm{IR}: \nu_{\max }^{\mathrm{CHCl}_{3}} 3450,1668 \mathrm{~cm}^{-1}$ ), yielded a significant amount of material after evaporation of $\mathrm{CH}_{2} \mathrm{Cl}_{2}$. The oil contaminant of fraction six was removed from the white crystals (ca. $0.012 \mathrm{~g}$; $10 \%$ of the crude mixture) by washing with a few drops of $\mathrm{CCl}_{4}$. Recrystallization of the white solid from cyclohexane yielded a white solid $10.0056 \mathrm{~g}$; m.p., $167-168^{\circ}$ on a microscope stage) whose HPLC showed a major peak at 14.5 minutes under the above conditions. T.l.C. of the solid on silica gel (IB-F) gave one spot $\left(\mathrm{R}_{\mathrm{f}}, 0.57\right)$ with $\mathrm{CH}_{2} \mathrm{Cl}_{2} /$ EtOAc (l:I) as the developing solvent. G.1.C. of the oil of fraction three (5\% SE-30; $\left.160^{\circ}\right)$ also showed a major peak at 17 minutes.

Purification of the crude photolysis mixture was also performed on a silica gel column using $\mathrm{CH}_{2} \mathrm{Cl}_{2}$, EtOAc or mixture of both as eluting solvents; $(7 \mathrm{~g}$ of silica gel Woelm was used to purify $0.38 \mathrm{~g}$ of crude oil; $20 \mathrm{ml}$ fractions were collected). The first two fractions eluted with $\mathrm{CH}_{2} \mathrm{Cl}_{2}$ contained a colorless.oil (IR: $\nu_{\max }: 2260 \mathrm{~cm}^{-1}$ ). N.m.r. of a sample of this oil (ca.40\%) was identical to the spectrum

* HPLC of 1-phenylcyclohexylacetamide showed a single peak with a retention time of 12 minutes under the same conditions. 
of the isocyanate produced* by the rearrangement of the corresponding acyl azide. $\quad(10 \mathrm{H}$, cyclohexyl, $1.48-2.14 \delta$; $2 \mathrm{H},-\mathrm{CH}_{2}-\mathrm{N}=\mathrm{C}=0,3.25 \delta^{\circ}$ and $5 \mathrm{H}$, phenyl, 7.28 .) Another major fraction eluted with $\mathrm{CH}_{2} \mathrm{Cl}_{2} /$ EtOAc (I:I) comprised a white solid contaminated with a yellow oil. This fraction $(0.059 \mathrm{~g})$ was further purified on another silica gel column (2.5 g; solvent $\mathrm{CH}_{2} \mathrm{Cl}_{2} /$ EtOAc, 4:1). The resulting crystals $(0.044 \mathrm{~g})$ were washed with $\mathrm{CCl}_{4}$ and then recrystallized from ethanol (m.p., $169-171^{\circ}$, on the microscope stage). The yield** of the white solid was approximately $13 \%$ (compared to $14 \%$ estimated from the gas chromatogram). A mineral oil mull of these crystals showed IR absorptions characteristic of a secondary amide (lactam?): $\nu_{\max }^{\text {Nujol }} 3350$, 1645, $1580 \mathrm{~cm}^{-1} ; \nu_{\max }^{\mathrm{CHCl}_{3}} 3450,1665 \mathrm{~cm}^{-1}$. N.m.r.: 8H, cyclohexyl, $1.48-1.60 \delta ; 2 \mathrm{H},-\mathrm{CH}_{2}-\mathrm{CO}, 3.14-3.18 \delta ; 1 \mathrm{H},-\mathrm{CH}-\mathrm{N}-$, $3.86 \delta ; 5 \mathrm{H}$, phenyl, $7.28 \delta$.

Another method used to separate the mixture was the precipitation of yellow crystals out of the crude photolysis oil on standing in $\mathrm{CH}_{2} \mathrm{Cl}_{2}$ for two weeks. The crystals were purified on a silica gel column $(2.5 \mathrm{~g}$ of silica gel;

*The isocyanate was prepared directly by thermal decomposition of the acyl azide at room temperature or, more efficiently, by refluxing the azide in hexane for two hours.

** When the acyl azide was irradiated in $\mathrm{CH}_{2} \mathrm{Cl}_{2}$ (Table III), the yield of the suspected lactam, purified on an alumina (grade III) column using hexane/benzene ( $9: 1$ ) as the eluting solvent, was much lower $(2 \%)$. 
$0.0562 \mathrm{~g}$ of material; ten 20-ml fractions were obtained). White crystals were isolated after evaporation of the solvent $\left(5 \%\right.$ EtOAC/ $\left.\mathrm{CH}_{2} \mathrm{Cl}_{2}\right)$ from the third and fourth fractions. HPLC of those fractions, using the analytical reversephase column $\mu \mathrm{C}-18$ (mobile phase, $\mathrm{CH}_{3} \mathrm{OH}$; pressure, 1500 psi; flow rate, $1 \mathrm{ml} / \mathrm{min}$ ) gave one peak component with a retention time of 4.5 minutes. A sample of the white crystals melted sharply in a capillary tube at $167.5-168^{\circ} \mathrm{C}$. Also, this solid exhibited the same IR absorptions ( $\nu_{\max }^{\text {Nujol }}$ 3350, $1645 \mathrm{~cm}^{-1}$ ) and n.m.r. chemical shifts as the suspected lactam isolated by the previous techniques.

One attempt to scale-up the reaction by doubling the concentration of acyl azide in the photolysis cell (photolysis $x x$, Table III) gave only a $4 \%$ yield of material corresponding to the amidic material described above. 
CHAP'TER V

\section{CONCLUSIONS}

1-Phenylcyclohexaneacetic acid azide has been synthesized from 1-phenylcyclohexaneacetic acid. The reaction sequence involved conversion of the carboxylic acid to the acid chloride and then to the acyl azide.

The irradiation of 1-phenylcyclohexaneacetic acid azide in hexane afforded 1-phenylcyclohexylmethyl isocyanate (ca. 40\%), a material tentatively identified as the o-lactam, 3-oxo-5-phenylmorphan (ca. 13\%) and an oil which was not identified. The isocyanate was produced by the rearrangement of the azide whereas the lactam resulted from. insertion of the intermediate acyl nitrene into $\mathrm{C}-\mathrm{H}$ bond of the cyclohexane ring.

The use of infrared and nuclear magnetic resonance data to determine the structures of the photolysis reaction products is discussed.

Even though the yield of the lactam was low, the photolysis of acyl azides. and acyl nitrene cyclization could become, by improving the yields, a useful method for the synthesis of heterocyclic organic compounds. 
SUGGESTIONS FOR FURTHER WORK

Clearly more work is required to fully elucidate the structure of the lactam (6). A pure sample for elemental analysis and a mass spectrum are needed*. Also a C-13 n.m.r. spectrum would be useful to confirm the structure. Detection of the resonance in the n.m.r. spectrum associated with the NH-proton could be accomplished by shaking a sample of (6) with deuterium oxide and repeating the spectrum. The active hydrogen would be replaced by deuterium and the integrator should indicate the disappearance of the NH resonance.

Another important factor to consider is maximizing the yield of the lactam by varying the photolysis conditions (solvent, concentration, temperature). Also different.. solvents or solvent compositions could be used in the separation of the products by chromatographic methods.

* One preliminary attempt to obtain a mass spectrum via the courtesy of Professors D. Borofsky and D. Daves of the Oregon Graduate Center gave anomalous results. 


\section{REFERENCES}

1. Apsimon, J.W. and Edwards, O.E., Can. J. Chem., 43. 896 (1962).

2. Balgir, B.S. and Mander, L.N, and Prager, R.H., Aust. J. Chem., 27, 1245 (1974).

3. Meyer, W. and Levinson, A. ' J. Org. Chem., 28, 2859 (1963).

4. Masamune, S., J. Am. Chem. Soc., 86, 290 (1964).

5. Brown, R.F.C., Aust. J. Chem.; 17, 47 (1964).

6. Antkowiak, W.; Edwards, O.E.; Howe, R., and Apsimon, J.W. , Can. J. Chem.; 43, 1257 (1965).

7. Huneck, S., Chem. Ber., 98, 2305 (1965).

8. Robinson, C.H. and Hofer, P., Personal Communication and 15lst Meeting, Am. Chem. Soc., Pittsburgh, PA, March 1966, Abstr. Papers K-19.

9. Zalkow, L.H.; Girotra, N.N. and Zalkow, V.B., J. Org. Chem., 32, 806 (1967).

']. Dobson, T.A.: Davis, M.A. and Hartung, A.M., Can. J. Chem., 46, 3391 (1968).

11. Beckman, A.O. and Dickinson; R.G., J. Am. Chem. Soc., $\underline{50}, 1870$ (1928).

12. Durr, H. and Kober, H., T. Curr. Chem., 66, 89 (1976).

13. Smolinsky, G. and Feuer, B.I., J. Am. Chem. Soc.; 86, 3085 (1964).

14. Yamada, S. and Terashima, S., Chem. Comm., 511 (1969); Chem. Abstr. 72:21571 p (1969).

15. Lwowski, W., Anqew. Chem. Internat. Edit., 6, 897 (1967).

16. Tisue, G.T.: Linke, S. and Lwowski, w., J. Am. Chem. Soc., 89, 6303 (1967). 
17. Linke, S.; Tisue, G.T. and Lwowski, W., J. Am. Chem. Soc., 89, 6308 (1967).

18. Brown, I. and Edwards, O.E., Can. J. Chem., 45, 2599 (1967).

19. Barltrop, J.A. and Coyle, J.D., "Excited states in Organic Chemistry", John Wiley and Sons, Inc., New York, NY, 1975 ; p. 128 .

20. Lwowski, W. and Mattingly, T.W., J. Am. Chem. Soc., 87, 1947 (1965).

21. Felt, G.R.; Linke, S. and Lwowski, W., Tetrahedron Letters, 2037 (1972).

22. Breslow, D.S. and Edwards E.I., Tetrahedron Letters, 2041 (1972.

23. Belloli, R.C.; Whitehead, M.A.; Wollenberg, R.H. and La-Bahn, V.A.' J. Org. Chem., 39, 2128 (1974).

24. Belloli, R.C. and La-Bahn, V.A.', J. Org. Chem., 40 , 1972 (1975).

25. Bachmann, W.E. and Fornefeld, E.J., J. Am. Chem. Soc., 73, 51 (1951).

26. Conley, R.T., "Infrared spectroscopy", 2nd Ed., Allyn and Bacon, Boston, 1972; p. 123, 124; 126; 167; 171; 180 .

27. Bellamy, L.J., "The Infra-Red Spectra of Complex Molecules", 3rd Ed., Methuen and Co., London, 1975; p. $141 ; 242 ; 246 ; 305,306$.

28. Nabors, J.B.; Miles, D.H.: Kumar, B; and Zalkow, L.H., Tetrahedron, 27, 2385 (1971).

29. Silverstein, R.M.; Bassler, G.C. and Morrill, T.C., "Spectrometric Identification of Organic Compounds", 3rd Ed., John Wiley \& Sons, 1974; p. 107; 137; 178; 308 .

30. Williams, D.H. and Fleming, I. "Spectroscopic Methods in Organic Chemistry", 2nd Ed., McGraw-Hili, 1973; p. $81 ; 85,86 ; 132 ; 139$.

31. Takeuchi, H.; Murata, N.; Nakagawa, Y.; Tsuchida, T. and Koyama, K., J.C.S. Perkin II, 80 (1977).

32. Lwowski, W. and Linke, S., Liebigs Ann. Chem., 8 (1977). 
APPENDIX

(spectra) 

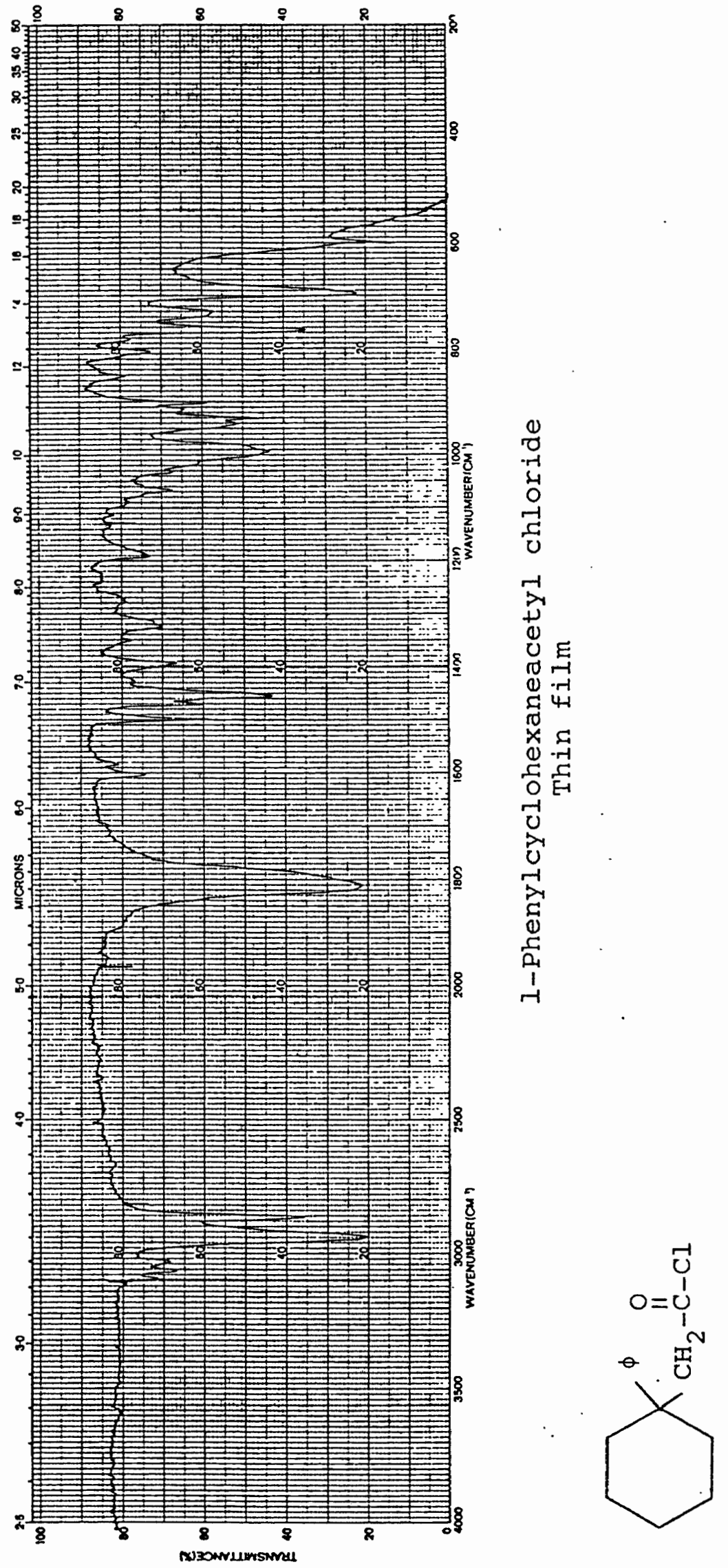


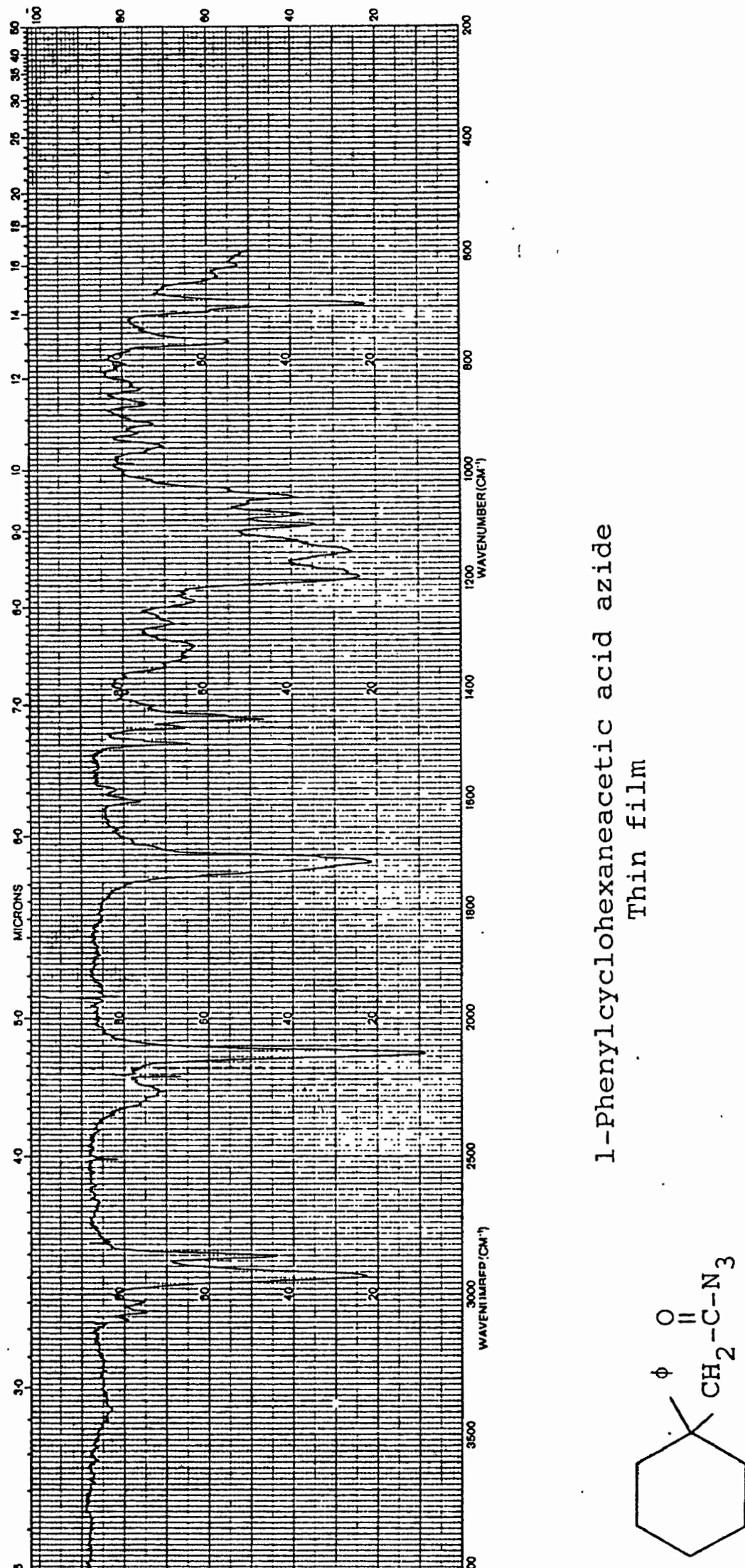




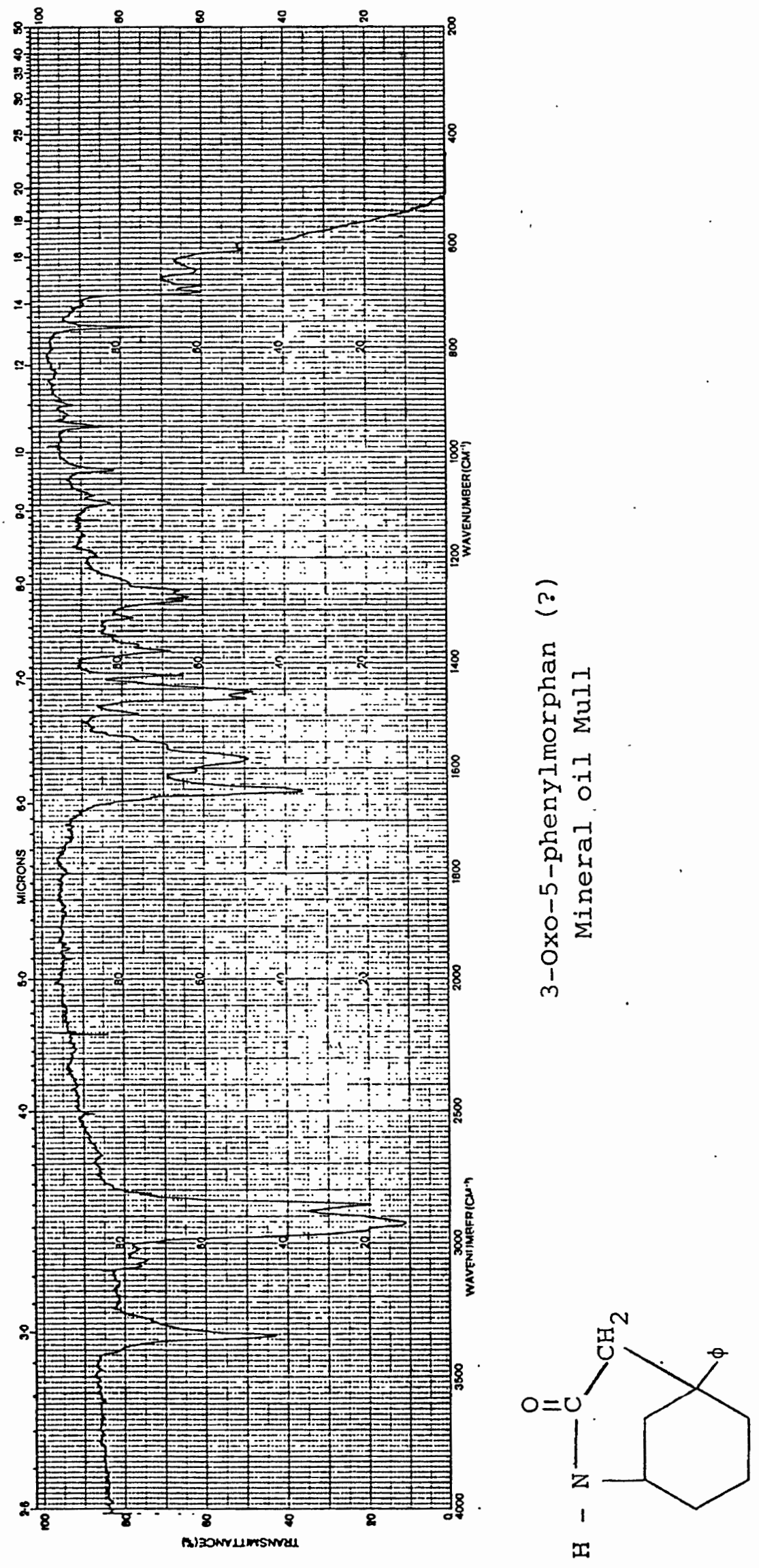




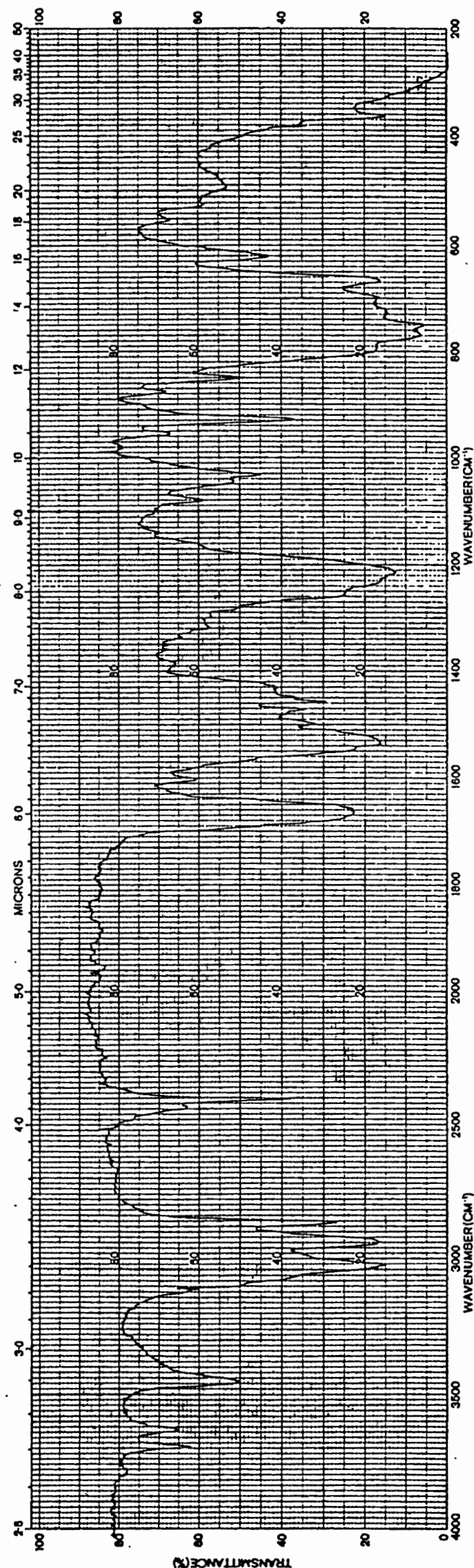

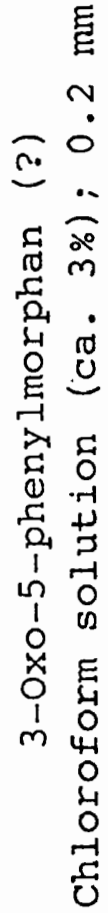

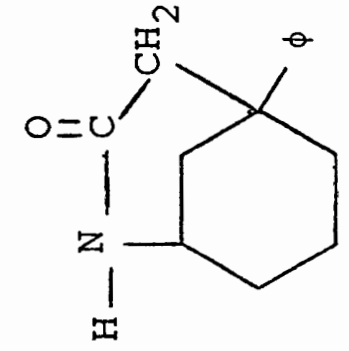



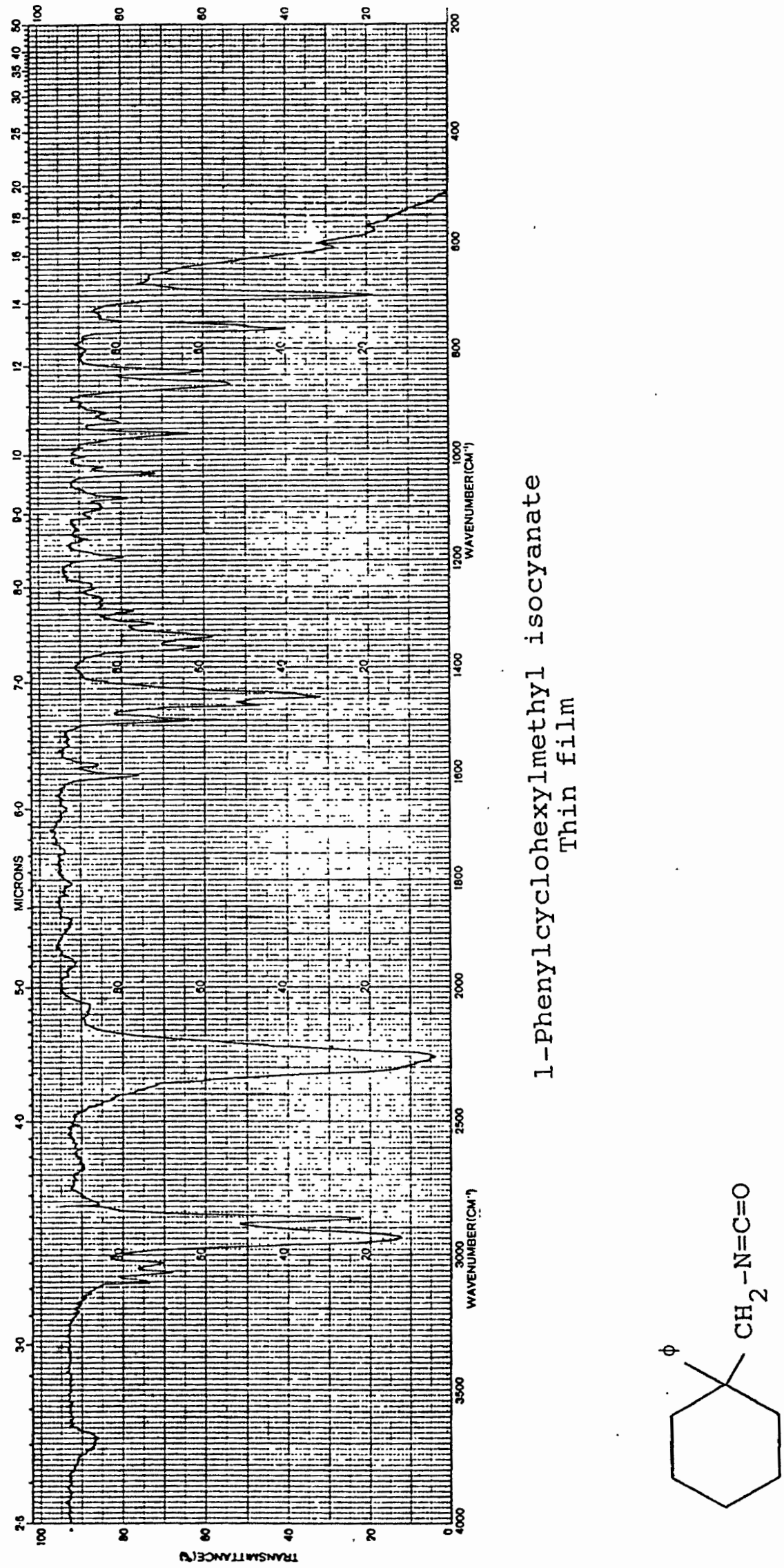


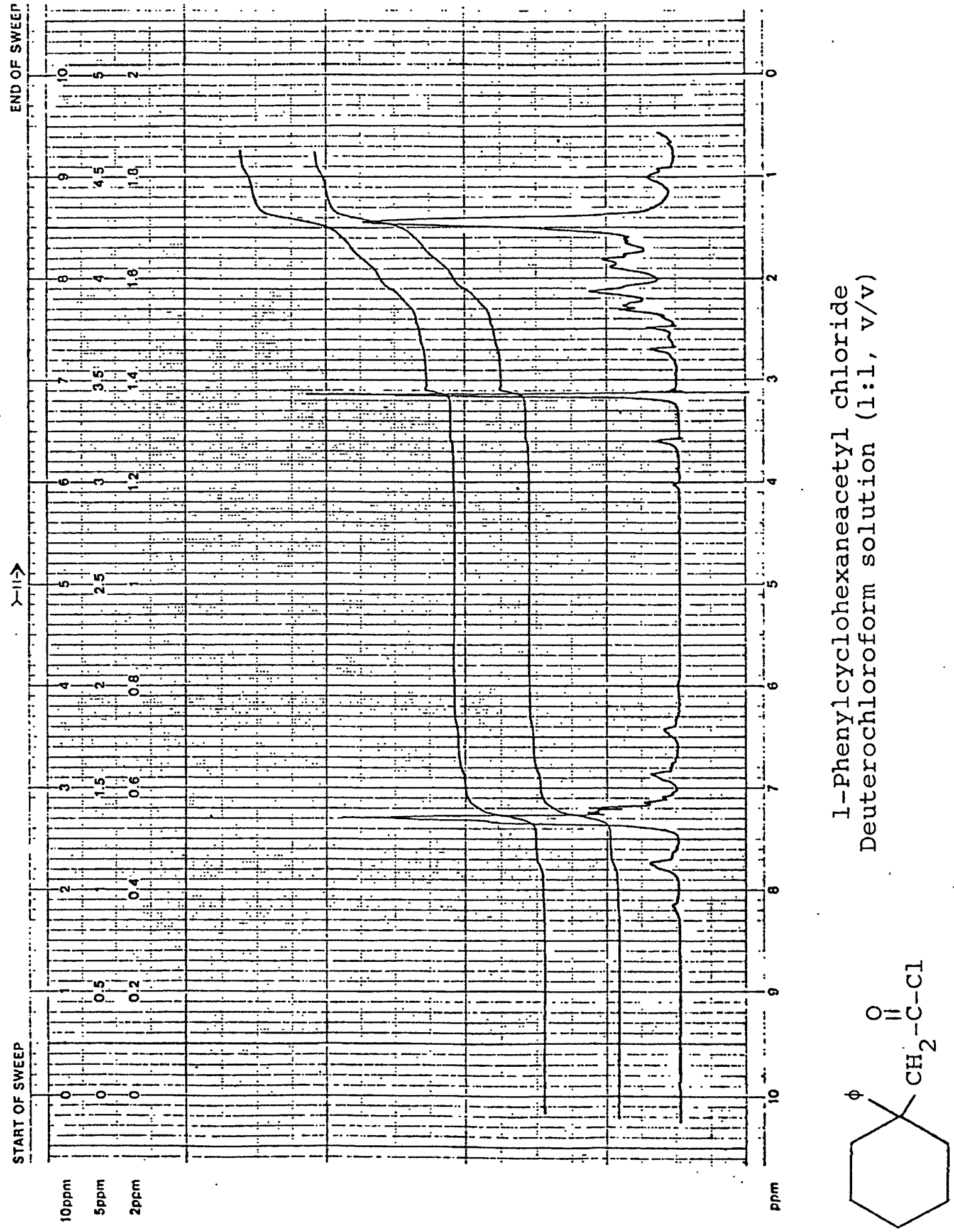




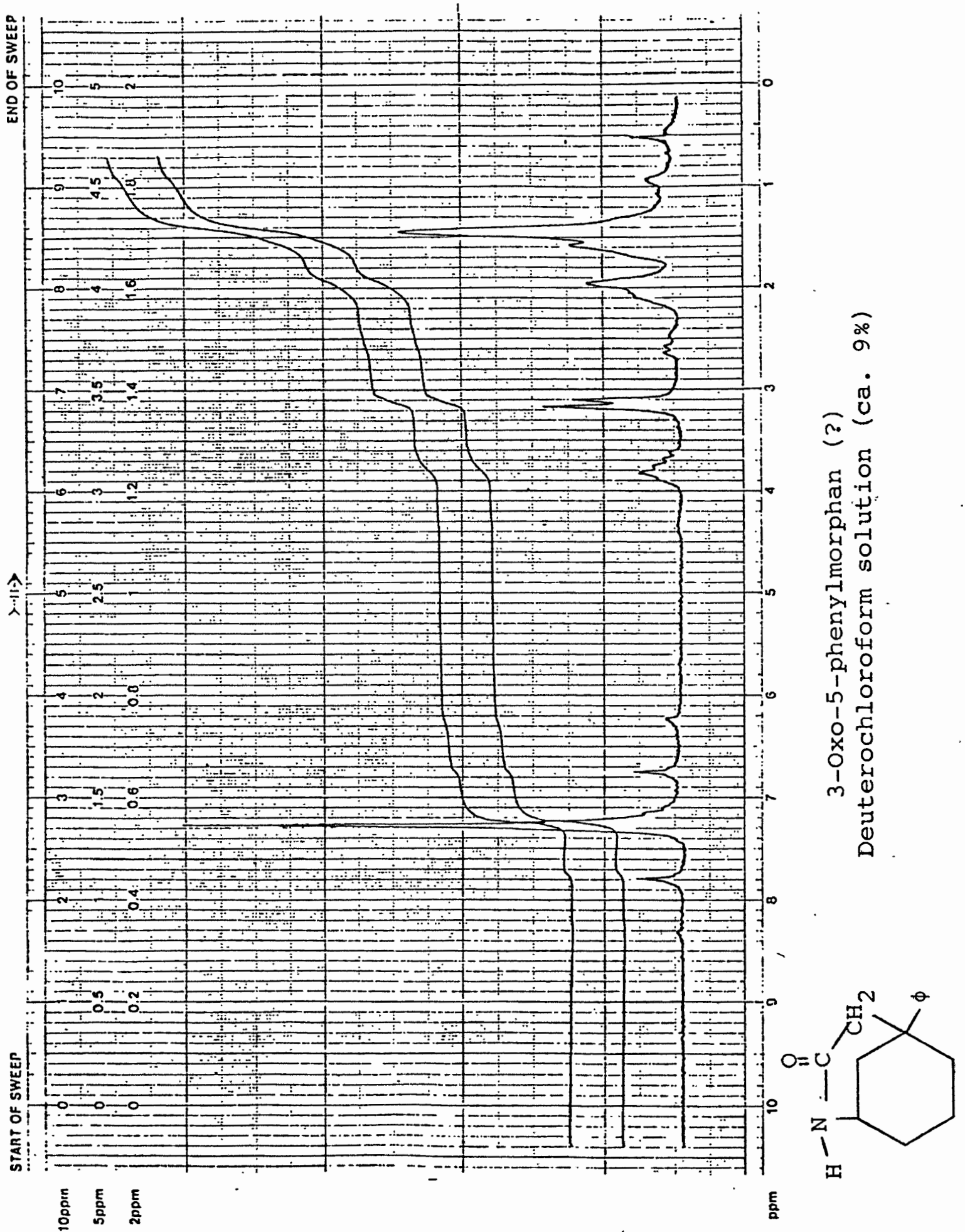




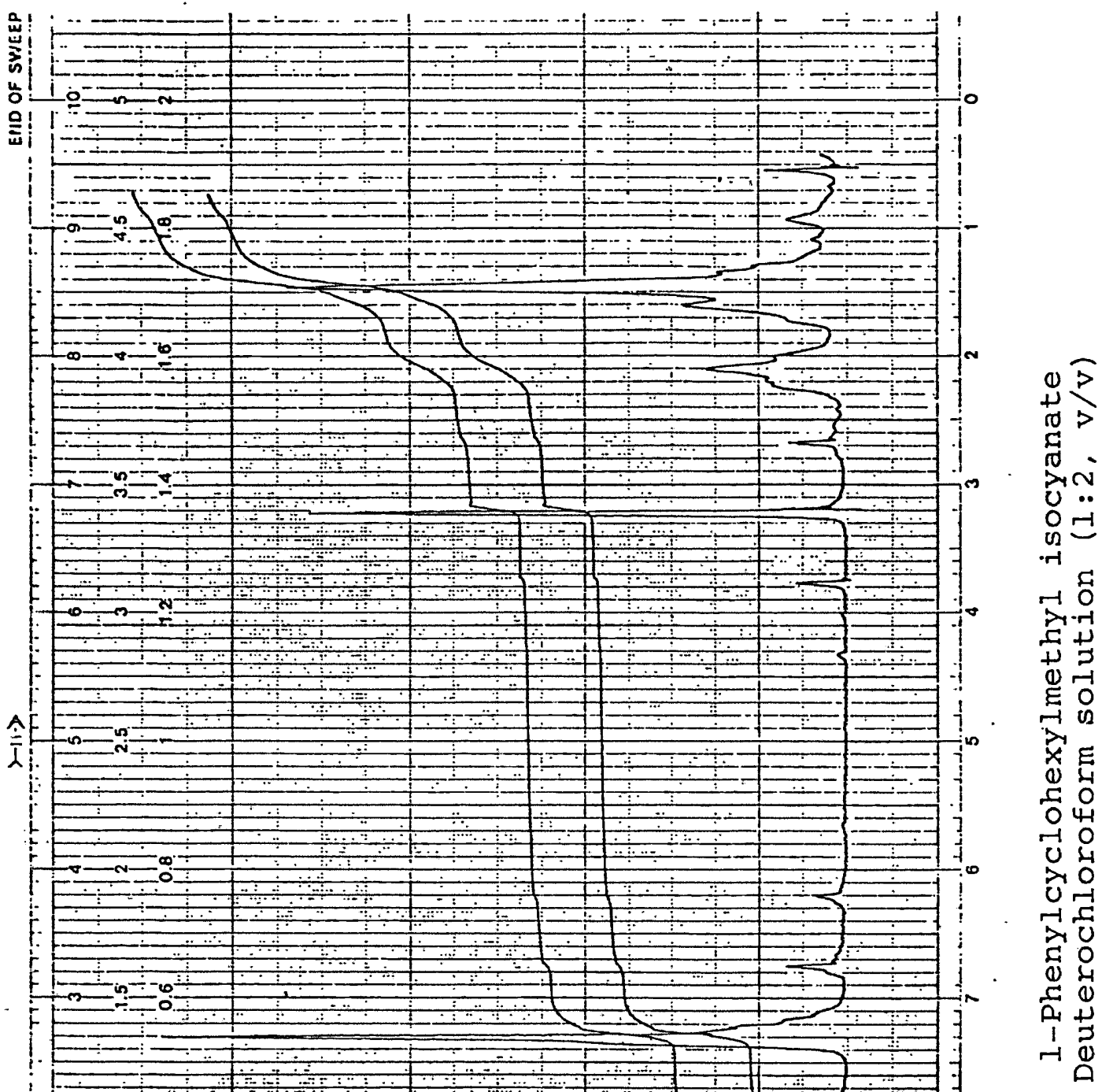

焉

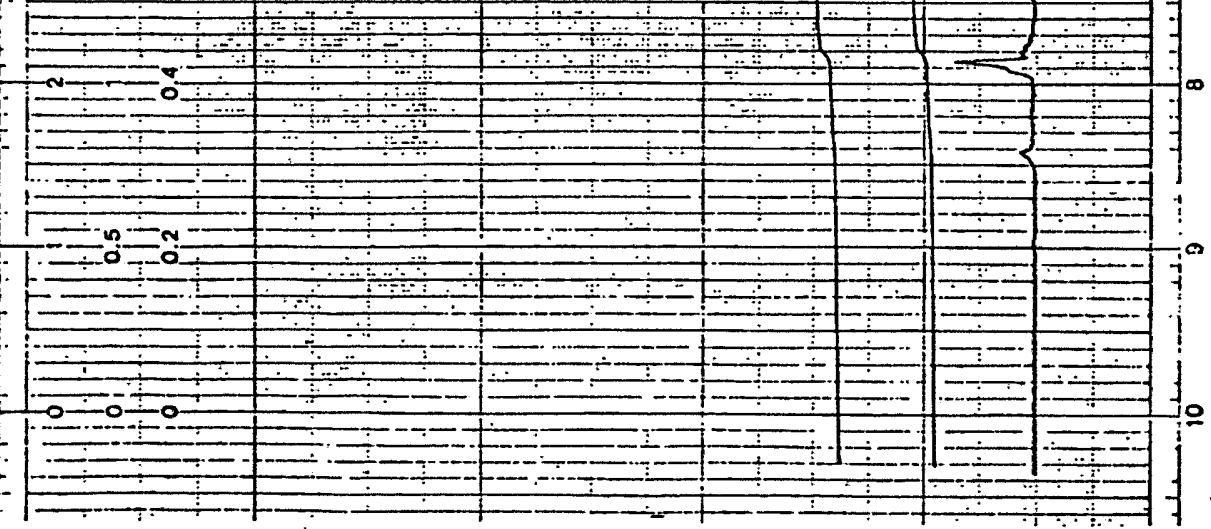

ำ

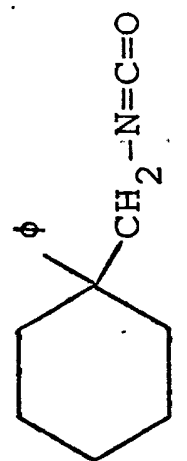

